\title{
Establishing Approaches to Modeling the Ares I-X and Ares I Roll Control System with Free-stream Interaction
}

\author{
S. Paul Pao, ${ }^{1}$ Karen A. Deere, ${ }^{2}$ and Khaled S. Abdol-Hamid ${ }^{1}$ \\ NASA Langley Research Center, Hampton, Virginia, 23681-2199
}

\begin{abstract}
Approaches were established for modeling the roll control system and analyzing the jet interactions of the activated roll control system on Ares-type configurations using the USM3D Navier-Stokes solver. Components of the modeling approach for the roll control system include a choice of turbulence models, basis for computing a dynamic equivalence of the real gas rocket exhaust flow in terms of an ideal gas, and techniques to evaluate roll control system performance for wind tunnel and flight conditions. A simplified Ares I-X configuration was used during the development phase of the roll control system modeling approach. A limited set of Navier-Stokes solutions was obtained for the purposes of this investigation and highlights of the results are included in this paper. The USM3D solutions were compared to equivalent solutions at select flow conditions from a real gas NavierStokes solver (Loci-CHEM) and a structured overset grid Navier-Stokes solver (OVERFLOW).
\end{abstract}

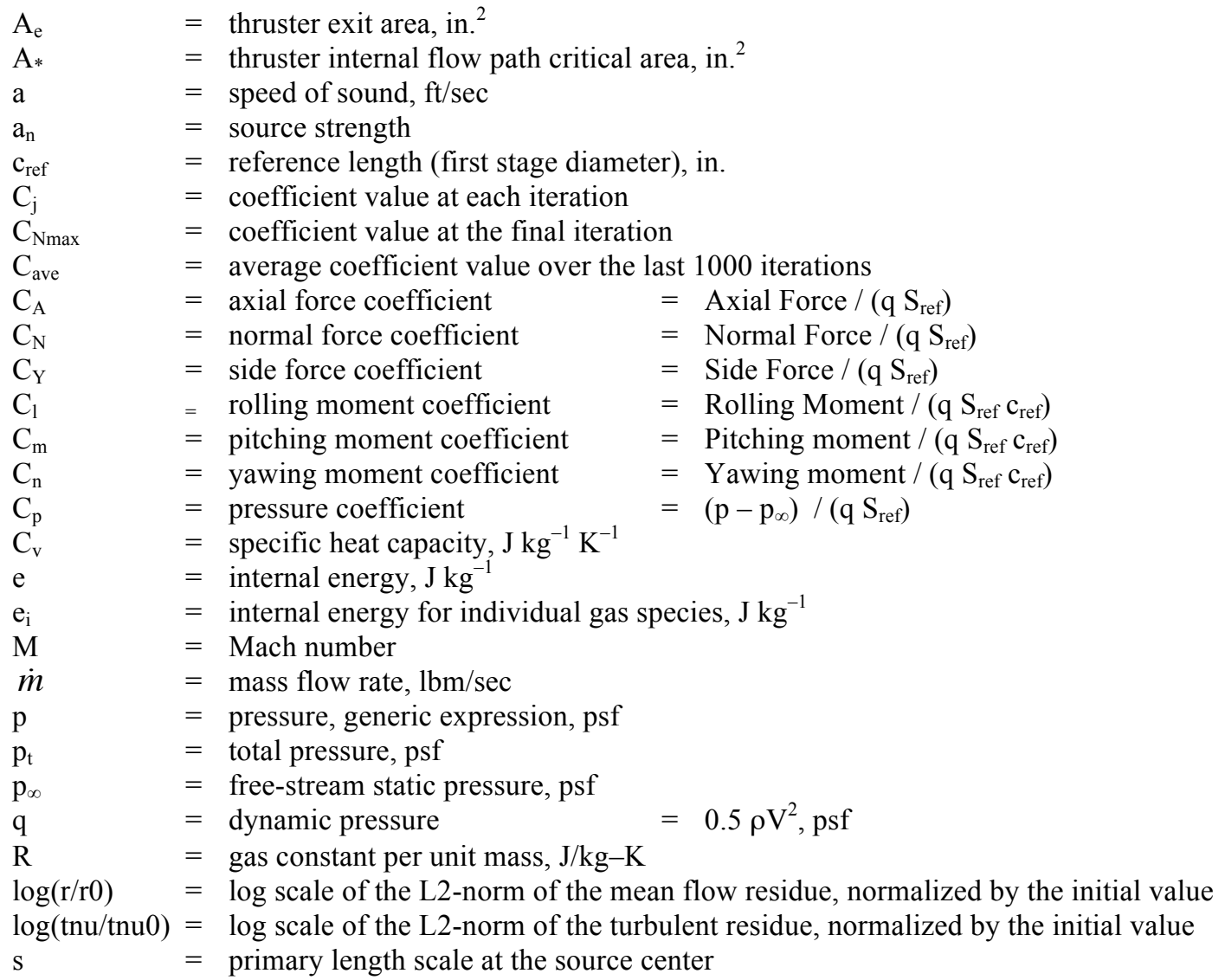

\footnotetext{
${ }_{1}^{1}$ Aerospace Engineer, Configuration Aerodynamics Branch, Research \& Technology Directorate, Mail Stop 499, and AIAA Associate Fellow.

${ }^{2}$ Aerospace Engineer, Configuration Aerodynamics Branch, Research \& Technology Directorate, Mail Stop 499, and AIAA Senior Member.
} 


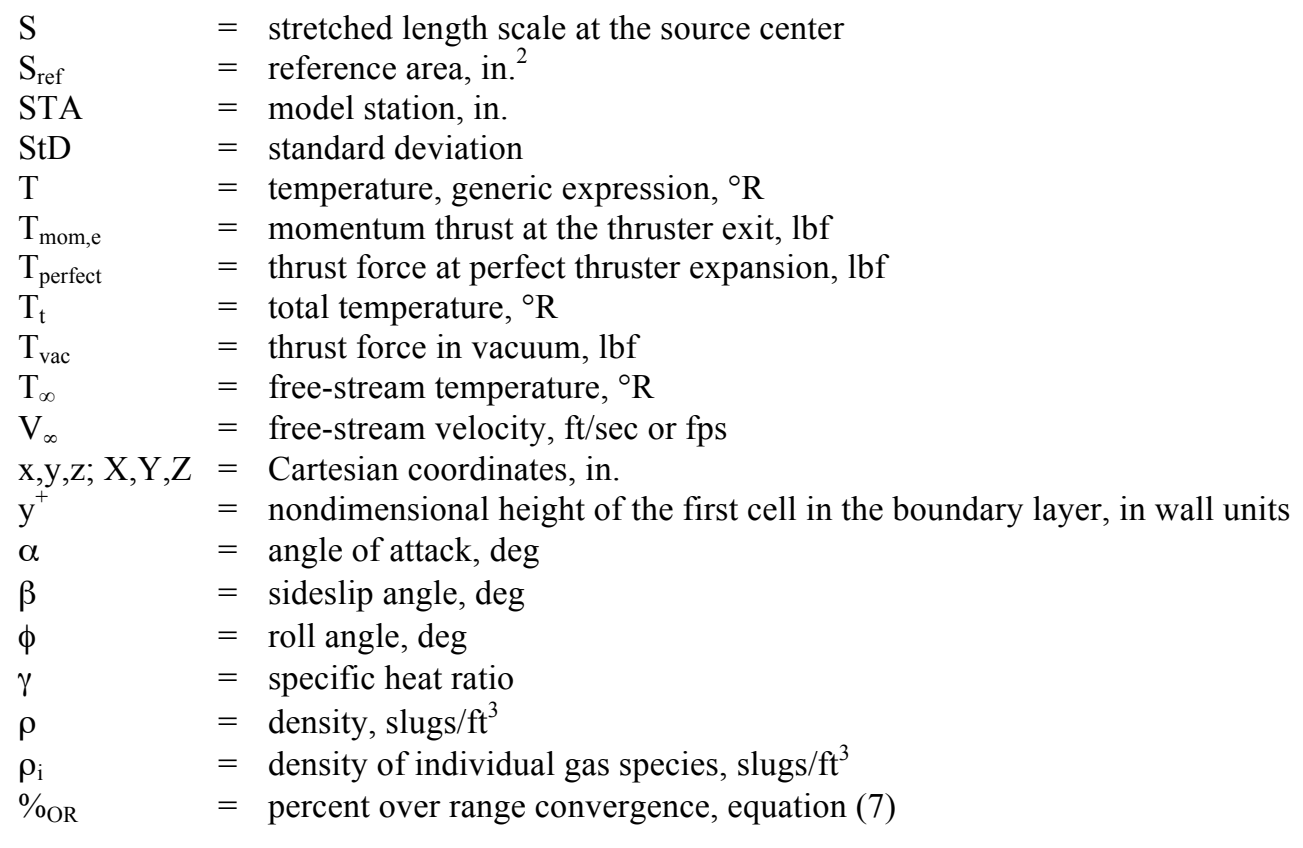

\section{Acronyms}

$\begin{array}{ll}\text { BTM } & =\text { booster tumbling motor } \\ \text { CFD } & =\text { computational fluid dynamics } \\ \text { CLV } & =\text { crew launch vehicle } \\ \text { dmybtm } & =\text { dummy booster tumbling motor } \\ \text { GN\&C } & =\text { guidance, navigation, and control } \\ \text { NAS } & =\text { NASA Advanced Supercomputing Division at Ames Research Center } \\ \text { PSWT } & =\text { Poly Sonic Wind Tunnel at Boeing, St. Louis MO } \\ \text { RoCS } & =\text { roll control system } \\ \text { SA } & =\text { Spalart-Allmaras [turbulence model] } \\ \text { SST } & =\text { Menter's Shear Stress Transport [turbulence model] } \\ \text { TetrUSS } & =\text { NASA Tetrahedral Unstructured Software System } \\ \text { UPWT } & =\text { Unitary Plan Wind Tunnel at NASA Langley Research Center }\end{array}$

\section{Introduction}

$\mathrm{D}$ ETERMINING the jet interaction effects of the roll control systems (RoCS) on the Ares I and I-X configurations was a challenging task because a best approach had not been established for modeling the complex flow interactions that occur between a chemically reactive jet plume from the RoCS and the free-stream airflow around a vehicle full of protuberances. Very few references were available for rolling moment analyses for the Ares I or Ares I-X vehicles. The work by Morris ${ }^{1}$ investigated the free-stream-to-plume interactions on installed rolling moment for a simplified and smoothed Ares I configuration using the Loci-CHEM software. Morris modeled the RoCS jet plumes with a simplified single species gas flow, matching the composition and specific heat ratio of an exhaust product composition based on 47.3 percent ammonia decomposition of monopropellant hydrazine. Reference 1 contains more details. However, Morris only modeled $180^{\circ}$ of the configuration, such that the flow field was symmetrical with respect to a mirrored symmetry plane for the left and right halves of the vehicle. A subsequent study by Ruf and Morris ${ }^{2}$ used a full $360^{\circ}$ mesh of the configuration to allow for the possibility of an induced swirl flow around the vehicle. The computational work of Meyer et al. ${ }^{3}$ and Daley et al. ${ }^{4}$ used the Ares I-X configuration for roll analysis with and without RoCS activated. The Ares I-X roll analysis in Ref. 3, using CFDFASTRAN software, included a code verification phase prior to computing production runs. A full flight scale mesh of the full protuberance DAC-2A geometry was analyzed at many Mach numbers, angles of attack, and roll angles. Daley et al. ${ }^{4}$ applied the roll analysis techniques developed by Meyer et al. to the RoCS rolling moment jet interaction effects on the Ares vehicle. Although the computational model for the vehicle and the flow conditions were different from the current work, results presented in Ref. 4 are valuable cross references to flow physics as 
seen from a different perspective. Finally, in this study the authors followed the computational fluid dynamics (CFD) best practice for Ares I configuration aerodynamics by Pao et al. ${ }^{5}$

Modeling the full chemical reactions of the flow in the thrusters, starting at the inflow plane of the rocket thruster plenum, was not computationally affordable for a parametric study with multiple thrusters on a high fidelity vehicle geometry in wind tunnel or flight flow conditions. Ideal gas modeling of the thruster flow was therefore considered for computational analyses. However, the substitution of ideal gas for real gas flow in the thruster required a computed equivalence of the inflow boundary condition and possibly a modification to the internal flow path geometry of the thruster nozzle. Options included using a full nozzle flow path starting from the plenum, using an inflow boundary condition starting at the exit plane of the thruster, or a compromise between these extremes by using a truncated thruster with an equivalent supersonic inflow boundary at a plane located between the throat and exit of the thruster. The turbulence model was another important factor in the computation for modeling the interaction between the rocket plume and the freestream. This study examined the one-equation Spalart-Allmaras and the two-equation SST model. In replacing real gas with ideal gas for computations using USM3D, it was feasible to match five quantities of the exit flow to the corresponding quantities of the original real gas thruster design values: density, velocity, pressure, mass flow rate, and thrust. Finally, grid density within the thruster nozzles and jet interaction zone was very important. However, the authors did not perform a grid study. Instead, they used the best grid generation practice from prior experience for modeling nozzle propulsion performance and plume and free-stream interaction to guide the grid generation for this study and subsequent parametric studies.

Results of the ideal gas thruster modeling in the USM3D calculations were compared with limited results from a Loci-CHEM real gas analysis of the full RoCS thruster internal flow path geometry and with an OVERFLOW ideal gas analysis with a boundary condition applied at the exit of the thrusters. Certainly, the ability to compare computational results with experimental data would be ideal, but no experimental data was available. The authors used as references a number of recent publications for other control jet interaction studies ${ }^{6-9}$ of other missile reaction control systems analyses or experimental measurements.

\section{Configuration Geometry and Coordinate System}

The computational surface geometry representing the simplified Ares I-X configuration ${ }^{10}$ included RoCS, dummy booster tumbling motors (BTMs) on the frustum, and a short sting. The computational geometry did not include stiffener rings and the aft-skirt on the first stage. Figure 1 shows the simplified first stage in red, the frustum and interstage in green, the RoCS housings in orange and blue, and a BTM in black. Parts of the vehicle shown in gray include the launch escape system, crew capsule, and the upper stage. Figure 2 shows the mesh on the interstage, frustum, RoCS housings, and BTMs. For Ares I-X, the thrusters inside the RoCS housing for clockwise roll are not aligned at the same vehicle axial position as the thrusters for counter clockwise roll. In order to show the alignment of the thrusters within the RoCS housing, in figure 2a the mesh is removed from the RoCS housing but is kept on the interstage, all thrusters, and frustum. Thrusters 1 and 3 are located downstream of thrusters 2 and 4 . Thrusters 1 and 2 are located in the same RoCS housing but on opposite vertical faces of the housing. Likewise, thrusters 3 and 4 are located in the same RoCS housing but on opposite vertical faces of the housing. Little impact was expected from the offset locations of the thrusters inside the RoCS housing, but the CFD analysis presented later in this paper indicates otherwise. It should be noted here that the Ares I RoCS thruster size and arrangements within the housing are different. The Ares I RoCS has six smaller thrusters in each housing, arranged three to each side and symmetrically between left and right.
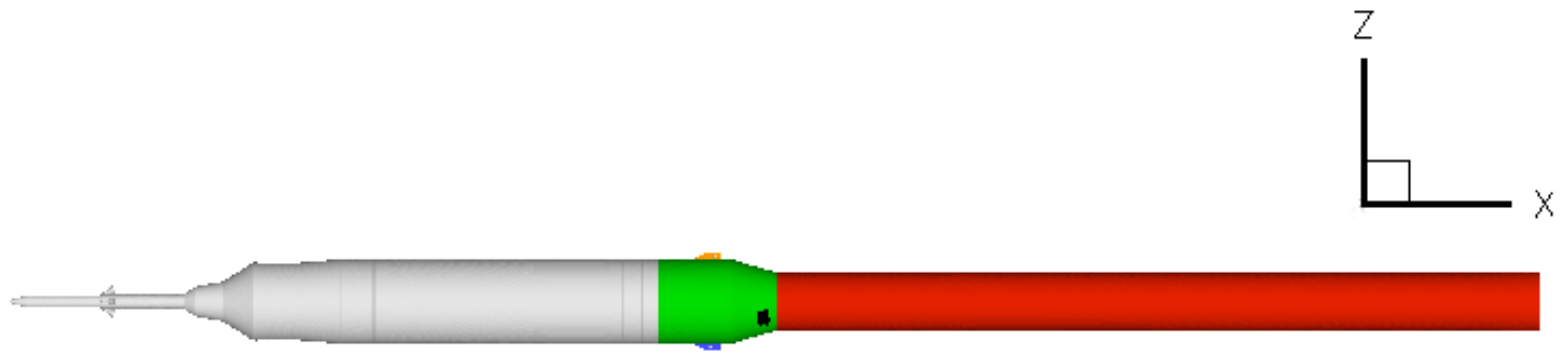

Figure 1. Computational surface for the simplified Ares I-X configuration: First stage with no aft skirt (red), interstage and frustum (green), and other components (gray). 


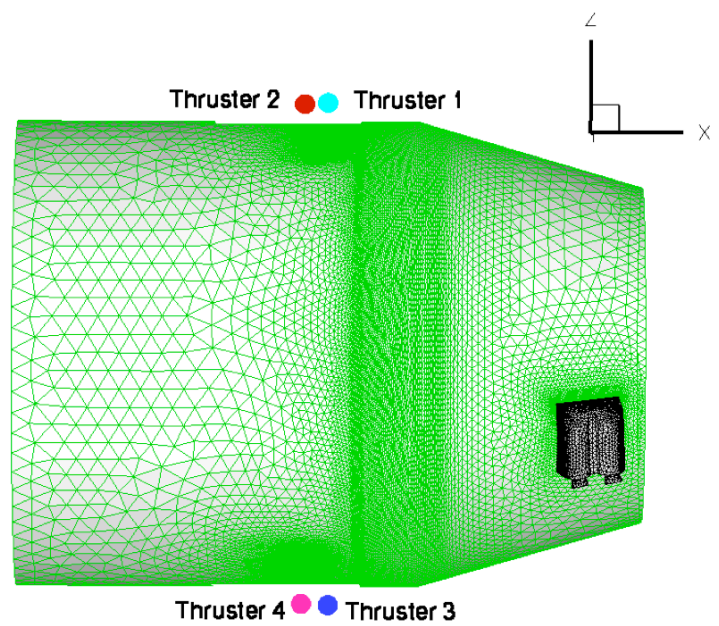

a) Thruster positions schematic.

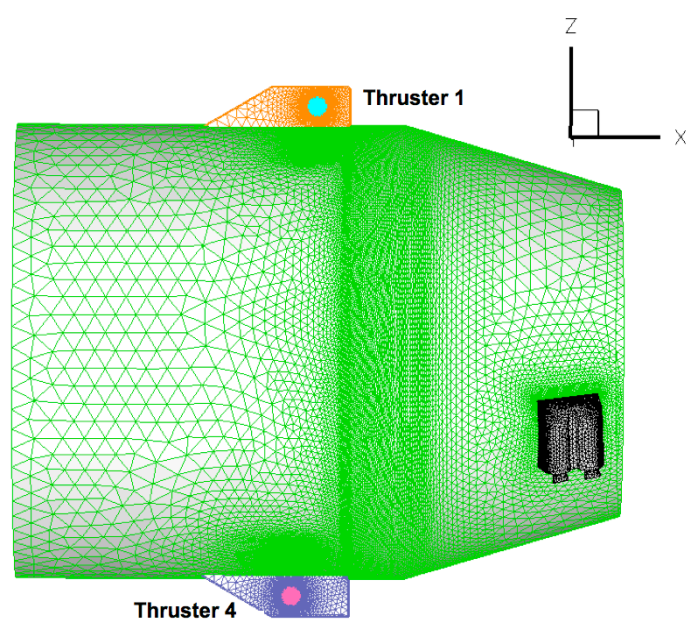

b) Thruster 1 and 4 located within housing surface mesh.

Figure 2. Ares I-X roll control system thruster positions within RoCS housing.

The reference coordinate system is shown in Fig. 3. For USM3D, the positive $\mathrm{X}$ axis $\left(\mathrm{X}_{\mathrm{CFD} \text { Domain }}\right)$ is the freestream flow direction, and the $\mathrm{Y}\left(\mathrm{Y}_{\mathrm{CFD} \text { Domain }}\right)$ and $\mathrm{Z}\left(\mathrm{Z}_{\mathrm{CFD} \text { Domain }}\right)$ axes are normal to the $\mathrm{X}$ axis to form a righthanded orthonormal coordinate system. Angle of attack is defined in the $X-Z$ plane, and sideslip angle is defined in the $\mathrm{X}-\mathrm{Y}$ plane. For this study, sideslip angle is zero $\left(\beta=0^{\circ}\right)$, and, thus, body axis angle of attack, $\alpha$, is equal to the missile axis total angle of attack, $\alpha_{T}$. The vehicle geometry is rotated along with the body axis system to investigate the effects of roll angle, $\phi$. Hence, the computed force and moment coefficients were in the missile axis system for guidance, navigation, and control (GN\&C) applications.

Throughout the text, a commanded positive rolling moment would fire thrusters to roll the vehicle clockwise as viewed by the pilot facing forward in the flight direction. Likewise, a negative rolling moment would result in rolling the vehicle counter-clockwise.

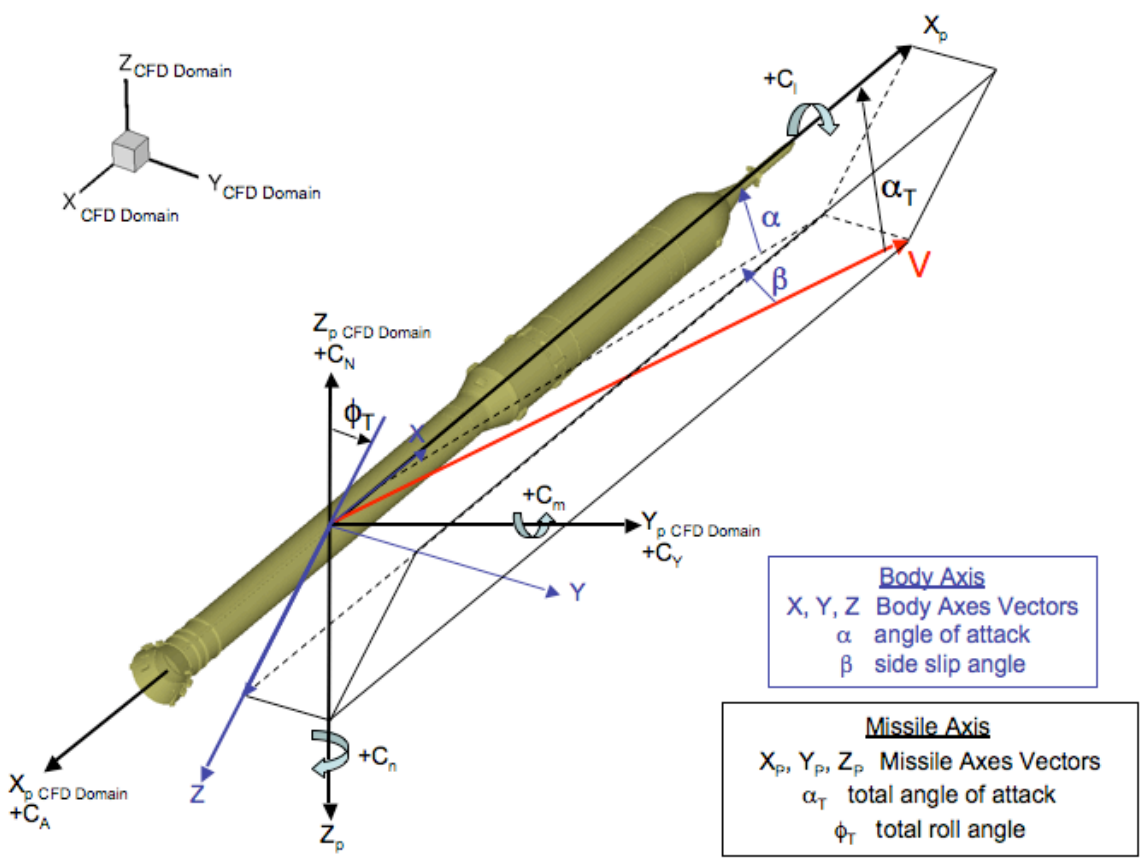

Figure 3. Reference coordinate system. 


\section{Methods Description}

The NASA Tetrahedral Unstructured Software System ${ }^{11-14}$ (TetrUSS), developed at the NASA Langley Research Center (LaRC), was used for this computational analysis. TetrUSS includes a surface model preparation tool (GridTool), grid generation software (VGRID, POSTGRID) and a computational flow solver (USM3D). The USM3D flow solver has a built in algorithm to calculate force and moment coefficients. Additionally, the authors analyzed the solutions with the NASA LaRC-developed code USMC6. ${ }^{15}$ Details of this software system and standard application procedures are provided in Refs. 11-14.

\section{Computational Flow Solver}

The USM3D flow solver is a tetrahedral cell-centered, finite volume Euler and Navier-Stokes (N-S) method. The authors used Version 6.0 of USM3D, updated February 2008 and identified as usm3d_60p.altix_sstcompcpd, for this study. USM3D has a variety of options for solving the flow equations and several turbulence models for closure of the N-S equations. ${ }^{12}$ This study used the implicit Gauss-Seidel scheme and the Roe flux differencesplitting scheme. The solutions had second order spatially accuracy. Menter's Shear Stress Transport (SST) turbulence model was used for all of the flow conditions. The authors also computed a few selected flow conditions with the Spalart-Allmaras (SA) turbulence model for turbulence model comparison purposes.

\section{Grid Density}

The overall unstructured mesh had 37.4 million cells and was designed with the first cell height above all viscous solid boundaries, sized to attain $\mathrm{y}^{+}$values of less than one for wind tunnel Reynolds numbers. Actual computations showed that the typical $\mathrm{y}^{+}$value was 0.6 for the $M=0.9$ cases and $\mathrm{y}^{+}=0.5$ for the $M=1.6$ cases. Surface mesh density varied according to the surface detail and expected flow complexity in accordance with the best practice procedures outlined in Ref. 5. Figure 4a shows the mesh inside the original thruster, designed appropriately for Loci-CHEM real gas analysis starting from the thruster plenum. Figure $4 \mathrm{~b}$ shows the mesh inside the truncated thruster designed appropriately for USM3D equivalent ideal gas analysis. The grid provided a turbulent viscous boundary layer mesh for the thruster nozzle interior wall.
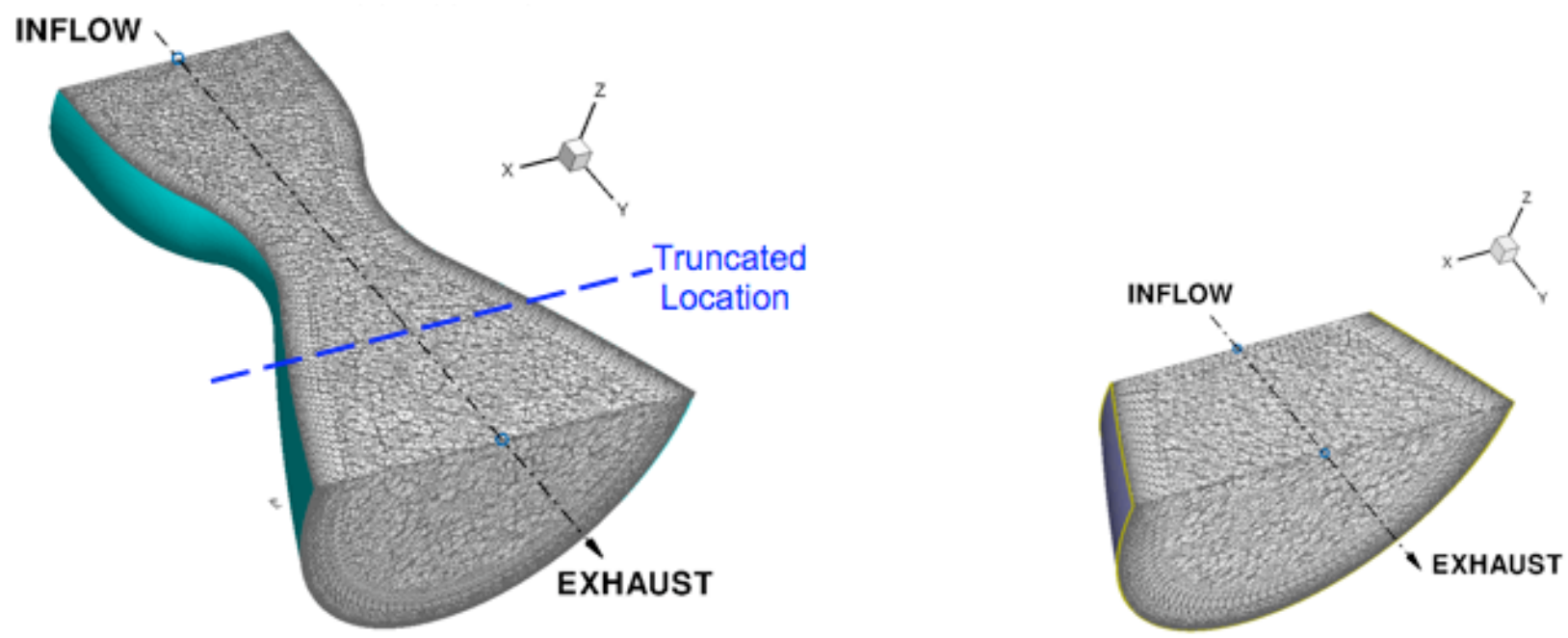

\section{a) Originial convergent-divergent thruster for real gas calculations.}

Figure 4. RoCS thruster computational model geometry.

The computational domain extended approximately twelve vehicle lengths in all directions. In terms of TetrUSS terminology, sources were used within GridTool to define where and how to cluster cells along the surface and near the configuration. Cylindrical, spherical, point, and linear source definitions were used to cluster cells around the many geometric shapes that make up the simplified Ares I-X vehicle. Of particular importance to the current study

$$
5
$$

American Institute of Aeronautics and Astronautics 
was the clustering of cells in the thruster internal flow path, the jet, and the free-stream interaction zone. Figure 5 illustrates the domain of the high-density grid and how the cylindrical sources were placed to accomplish such density distribution. Approximately four million cells were clustered in every funnel shaped region associated with each of the four thrusters. The remaining 21 million grid cells, serving mainly configuration aerodynamic purposes, were consistent with the cell count for an Ares vehicle mesh constructed according best practice without an active RoCS systems or other protuberances onboard.

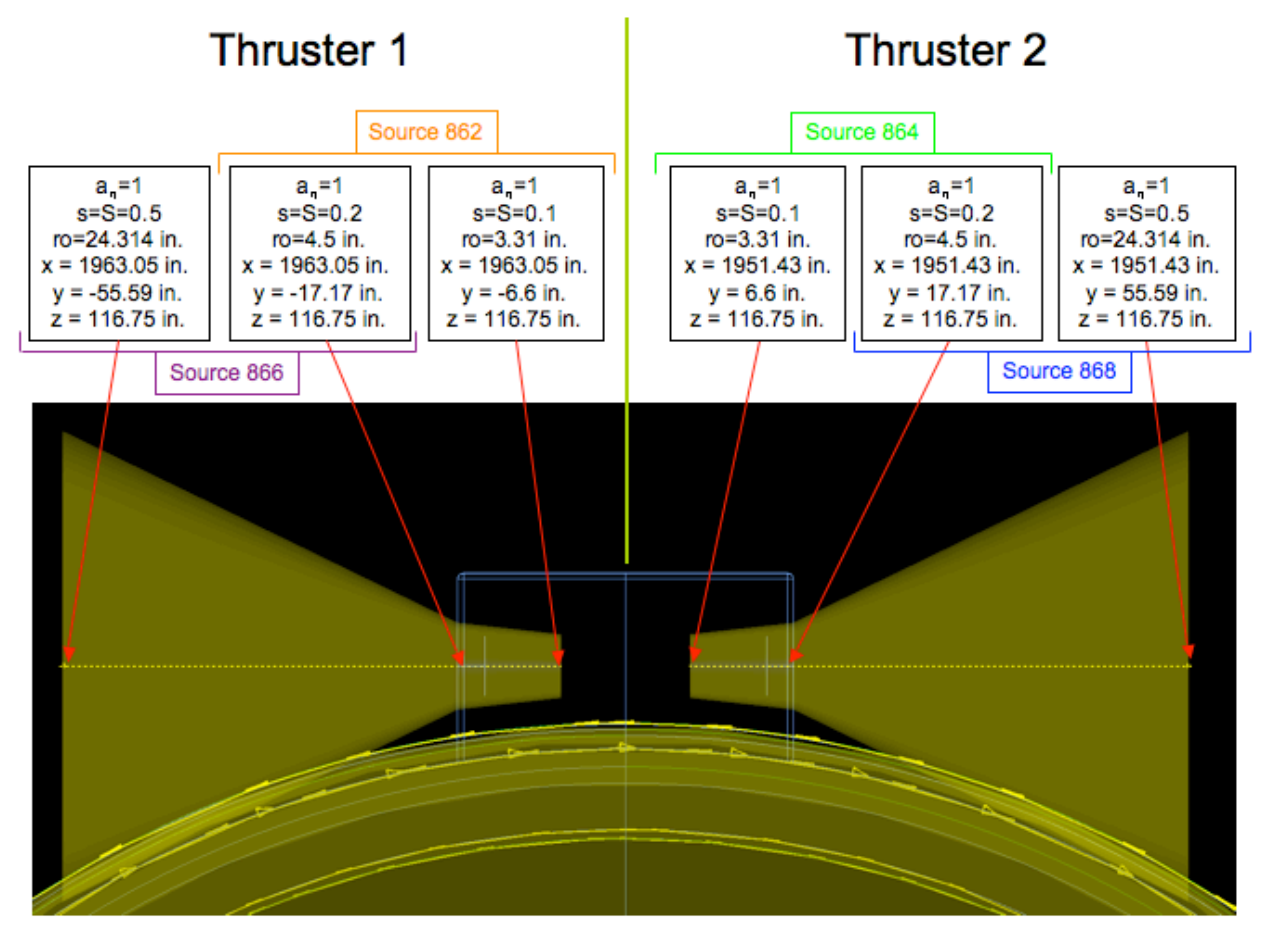

Figure 5. Cylindrical sources used to define the cell size and clustering in and around thruster-1 and thruster-2; RoCS housing outlined indicated in light blue.

\section{Ideal Gas Inflow Equivalence to Real Gas Thruster}

The ideal gas analysis can match five parameters at the rocket thruster exit: density, pressure, velocity, mass flow rate, and thrust. Once one knows the exit condition, one may recover the inflow boundary condition for a full or truncated nozzle through one-dimensional aerodynamic equations. Therefore, the overall analysis provides correct values of mass, volume, and momentum injection from the thruster to the external flow. Matching exit pressure is important because it is an installed thrust analysis prerequisite. The ideal gas equation of state is:

$$
p=\rho R T
$$

The real gas effects are often expressed as high order terms of temperature added to this equation. If the thruster exhaust flow is idealized at a frozen chemical composition, it would obey Eq. (1). Once pressure P, and density $\rho$, are chosen, the value of $R T$ is fixed. The molecular weight of the idealized thruster exhaust and air, as employed in this study, are different. The value for the gas constant $R$ per unit mass is inversely proportional to molecular weight. While ideal air has a higher molecular weight than the thruster exhaust, its temperature must be higher than the temperature of the thruster exhaust gas in order to maintain a constant value of $R T$. The equation for speed of sound is given by:

$$
a=\sqrt{\gamma R T}
$$


Again, $\gamma$ is different between ideal air and the thruster exhaust gas. While the value of $R T$ remains the same, the change in the speed of sound is based entirely on $\gamma$. As the speed of sound for the equivalent ideal gas has changed and the exit velocity $\mathrm{V}$ is specified as the same as before, a new nozzle exit Mach number is now:

$$
M=V / a
$$

Matching mass flow rate and momentum thrust follows from matching the values of density and velocity:

$$
\begin{gathered}
\dot{m}=\rho V A_{e} \\
T_{m o m, e}=\rho V^{2} A_{e}=\dot{m} V
\end{gathered}
$$

In a preliminary study in search of a best approach for installed RoCS CFD analysis, several thruster geometries and flow matching concepts were investigated. These included a full plenum to exit flow path with a modified throat diameter, the original full nozzle, a truncated nozzle with coaxial inflow velocity vector, and a truncated nozzle with splayed velocity distribution between the axis and the diverging nozzle wall. The last option was found to be the best. Figure 6 shows an example of the truncated splayed velocity thruster technique, with streamlines and Mach contours shown in the center-plane of the thruster. Beginning at the truncated thruster inflow plane, the velocity angle in reference to the nozzle axis gradually increases from zero (velocity aligned along the axis) to an angle providing a velocity vector tangent to the thruster wall. The truncated splayed velocity thruster configuration provided the best match of average exit flow conditions with the corresponding original real gas thruster performance parameters. Although exit temperature was not matched, the thermodynamically significant value of $R T$ in the original real gas flow was preserved.

The following process was used for determining the RoCS thruster ideal gas inflow boundary condition for the truncated thruster design. First, the averaged flow quantities at the real gas thruster exit plane were computed as references for matching. The authors derived temperature and the speed of sound from the equation-of-state for air and computed an exit Mach number with the given speed of sound to match the exit flow velocity using Eq. 3 and 4. The exit plane averaged pressure and density were chosen to be the original rocket thruster values. Matching thruster mass flow rate and thrust followed automatically from the matched values of density, velocity, and the unchanged thruster exit area using Eq. 5 and 6 . The authors determined a virtual throat area by using onedimensional aerodynamic equations and the ideal gas thruster exit Mach number:

$$
\frac{A_{*}}{A}=\left(\frac{\gamma+1}{2}\right)^{\frac{\gamma+1}{2(\gamma-1)}} M\left(1+\frac{\gamma-1}{2} M^{2}\right)^{\frac{-(\gamma+1)}{2(\gamma-1)}}
$$

The same equation was used to determine the Mach number at the inflow plane by using the area ratio between the inflow plane and the virtual throat area, $\mathrm{A} *$. The truncated inflow plane was located in the divergent section of the thruster such that the inflow Mach number was supersonic. The authors computed the averaged Mach number, density, pressure, and supersonic velocities at the inflow plane through standard perfect gas compressible flow equations according to the Mach number at the inflow plane. Finally, the flow variables were distributed over the inflow plane according to the original real gas thruster exit plane distributions while maintaining the matched inflow plane average values, and the velocity vector was splayed out from the center to the thruster walls. A viscous boundary layer condition was used on all solid surfaces. At the truncated inflow faces, a supersonic inflow boundary condition was used on the firing RoCS thrusters, while an inviscid solid boundary condition was used on idle thrusters. A supersonic inflow boundary condition was used at the inflow face of the computational domain and an extrapolation boundary condition was used at the downstream outflow face of the same domain. A characteristic inflow/outflow boundary condition was used for the lateral faces of the domain.

\section{Thruster Model Geometry Selection for USM3D}

A component study of thruster model geometry was conducted early in this study to select the best combination of thruster internal flow path geometry and thruster inflow boundary condition. The original nozzle geometry came from the rocket motor design. Hence, that geometry was used for the Loci-CHEM jet interaction of the simplified Ares I-X vehicle with an active RoCS system. For the USM3D ideal gas computations, the authors examined a 
number of options: a truncated nozzle with an axial inflow velocity vector, a truncated nozzle with a splayed inflow velocity vector, and a full flow path nozzle geometry with initial total temperature and pressure conditions in the plenum chamber, among others. The full nozzle flow path approach using a plenum boundary condition gave the worst match to the original performance of the thruster. It was because that the nozzle shape was designed for a perfect supersonic expansion of the real rocket gas medium with reacting chemical components and a variable $\gamma$. Computations using the same shape with a fixed $\gamma=1.4$ ideal gas thus resulted in a poor supersonic flow expansion through the nozzle and a poor match with the original rocket flow parameters at the exit plane. The truncated nozzle with splayed inflow velocity vector approach was clearly a good compromise and the best choice for this study. Figure 6 shows the smoothness of flow inside the truncated nozzle using a splayed inflow velocity vector approach.

While the inflow boundary condition was derived from the original averaged flow parameters of the thruster through one dimensional perfect gas equations, the original sectional distribution across the nozzle exit face could not be duplicated by the ideal gas solution. Figures 7 and 8 show the difference in distributions of static pressure, density, axial velocity, and static temperature. Although the distribution of $p, \rho$, and $V$ are not the same as the original distribution, their averaged values across the thruster exit plane come very close to their respective original values for the real gas thruster flow. As mentioned earlier in this section, the averaged temperature for the equivalent ideal gas flow is higher than the original, while the value $R T$ remains the same. The main jet interaction effect is dominated by momentum exchange between the thruster exhaust flow and the free-stream. The temperature effect may affect heat transfer, but not forces and moments that are the main objectives of this study.

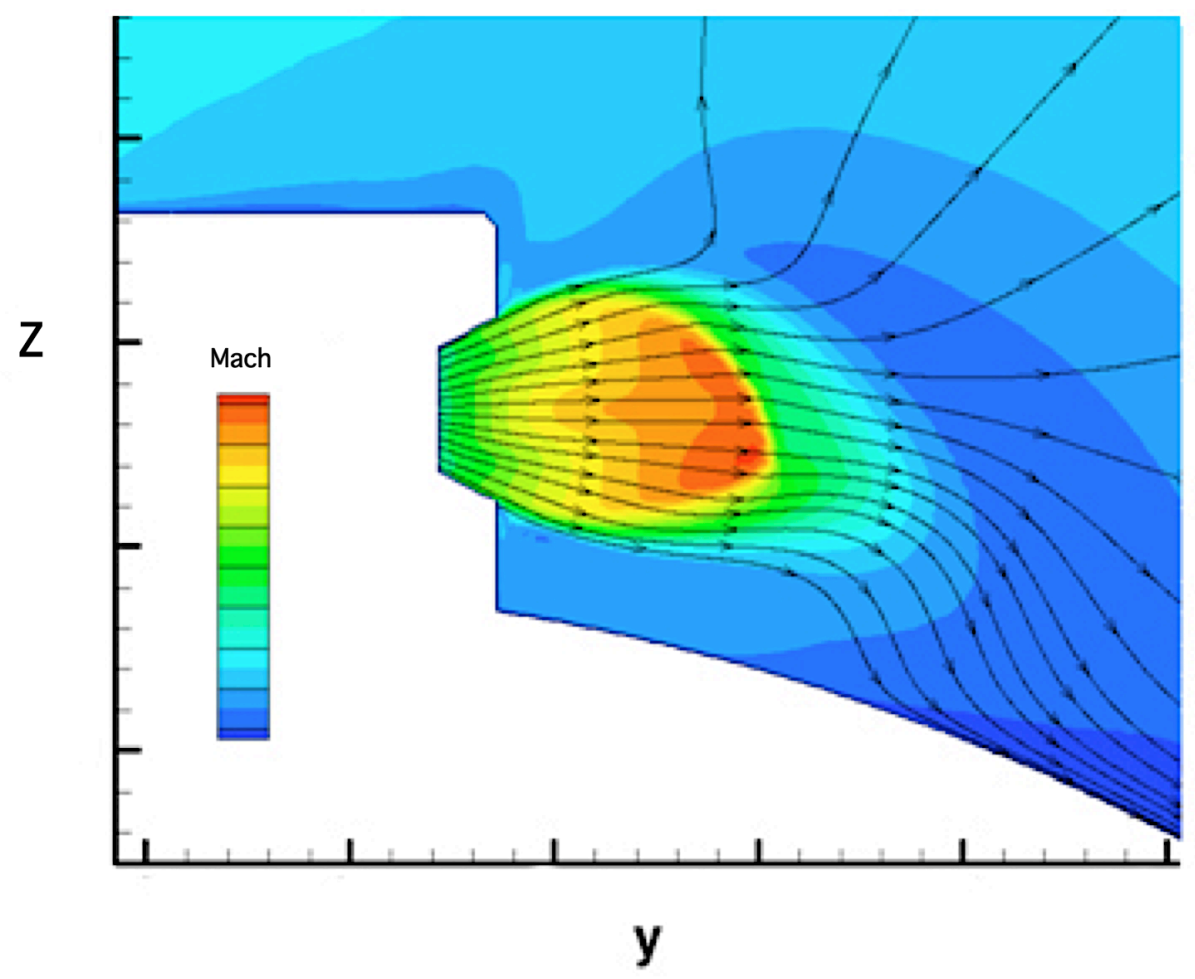

Figure 6. Splayed exit velocity technique inside the truncated thruster, $M=1.6, \alpha=0^{\circ}$, and the thrusters firing for a negative rolling moment. 

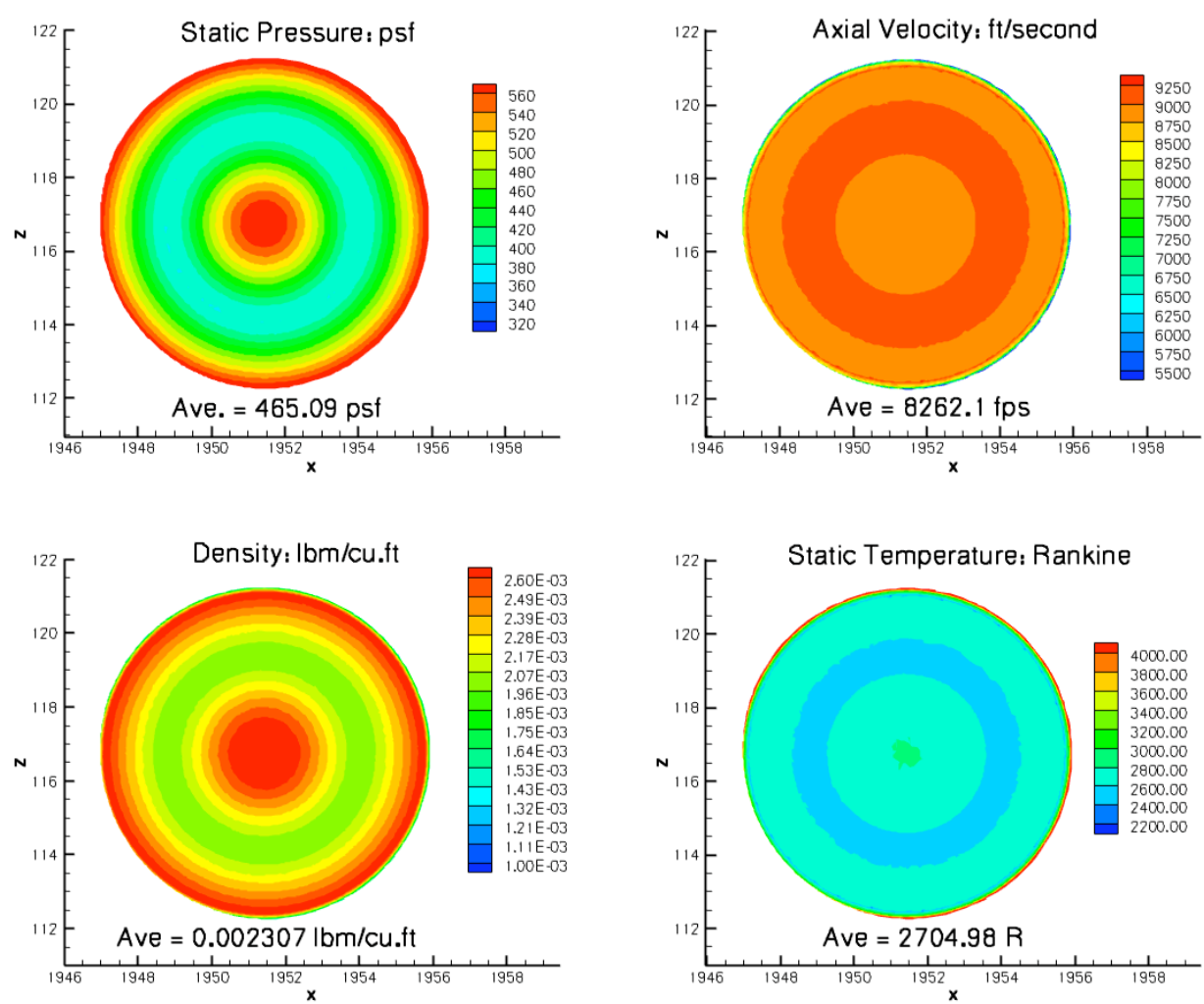

Figure 7. Averaged flow quantities at the real gas thruster exit.
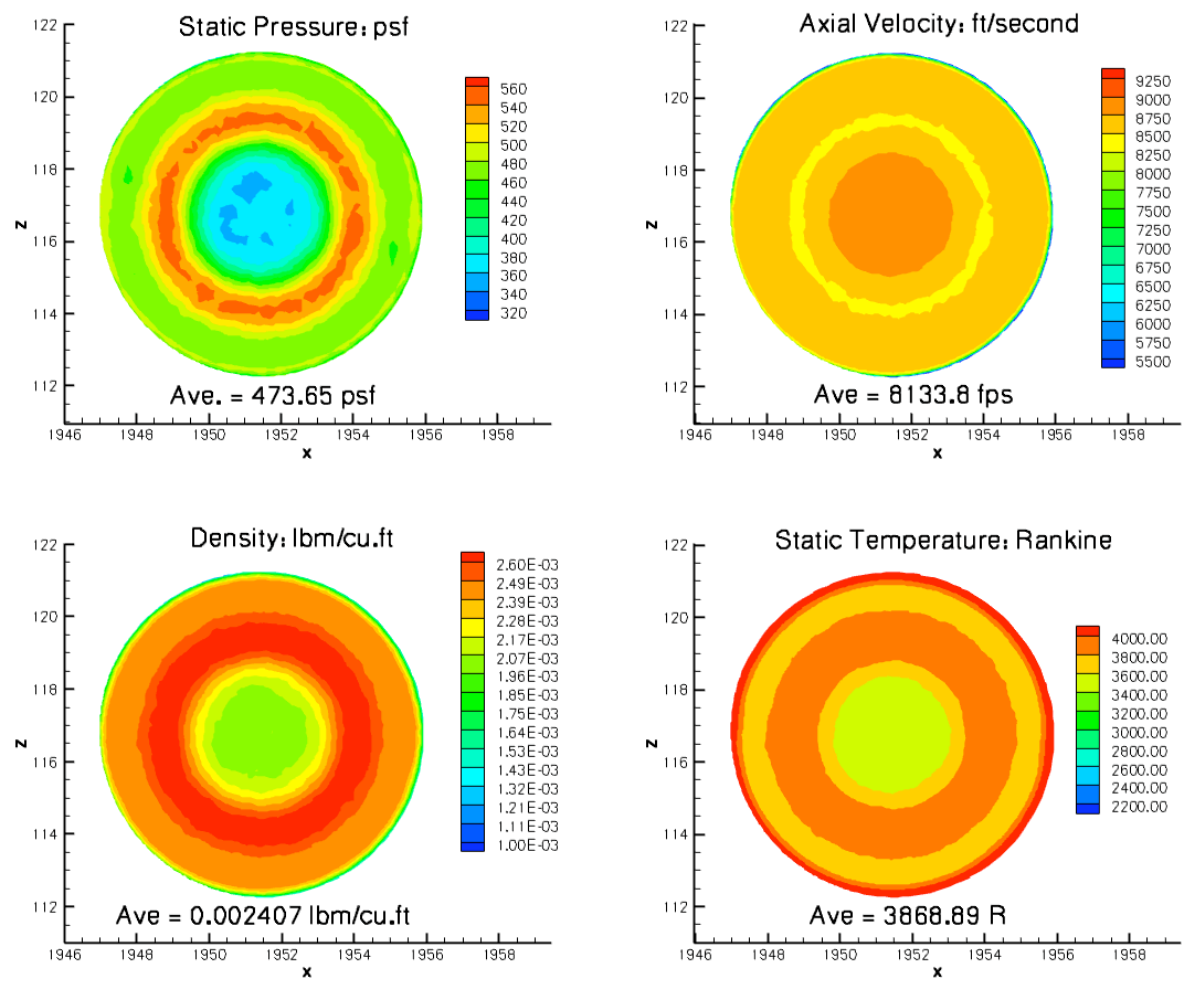

Figure 8. Exit flow conditions using the final matched inflow boundary condition. 


\section{Solution Quality Assurance}

The jet interaction effect on RoCS performance is a very small quantity in absolute terms. In fact, launch vehicle rolling moment itself can be small and difficult to compute or to measure in a wind tunnel test. Hence, it is very important in this study to assure the quality of the solutions was sufficiently accurate to bear the small differences in rolling moment as a result of jet interaction. The following sections describe the convergence criteria, the grid resolution study, the turbulence model assessment, and the comparisons of USM3D data with limited comparisons to solutions by OVERFLOW and Loci-CHEM. Although the SST turbulence model was chosen for the limited parametric study documented in the results section, some comparisons with SA solutions are shown. Additionally, since the ideal gas solutions from OVERFLOW used the SA turbulence model, the USM3D data comparison with OVERFLOW contained only data with the SA turbulence model.

\section{Convergence}

To monitor and determine solution convergence, the authors used two criteria: decreasing solution residuals and a bound on changes of force and moment coefficients at the end of the iterative solution process. Figure 9a shows examples of solution convergence history plots. First, a drop in residual of at least three orders of magnitude was desired for $\{\mathrm{r} / \mathrm{r} 0\}$. Second, the convergence of force and moment coefficients was evaluated with a percent-overrange $(\%$ OR $)$ value of less than 0.5 percent of each coefficient averaged over 1000 iterations. The standard deviation and $\%_{\mathrm{OR}}$ were also calculated for each coefficient. The $\%_{\mathrm{OR}}$ was calculated by equation 7 , where $\mathrm{C}_{\text {jmax }}$ is the value of the coefficient at the last iteration. Additionally, a history plot of the coefficients with respect to iteration is helpful to visually determine the convergence of the coefficients, especially when a coefficient is near zero. Figure $9 \mathrm{~b}$ shows a typical solution history of the force and moment coefficients. Each coefficient flattens out to a constant value for a converged solution.

$$
\begin{gathered}
\%_{O R}=\frac{C_{N_{\max }}-C_{\left(N_{\max }-999\right)}}{C_{a v e}} \times 100 \% \\
\text { where: } C_{\text {ave }}=\frac{1}{1000} \sum_{j=N_{\max }-999}^{N_{\max }}\left(C_{j}\right)
\end{gathered}
$$

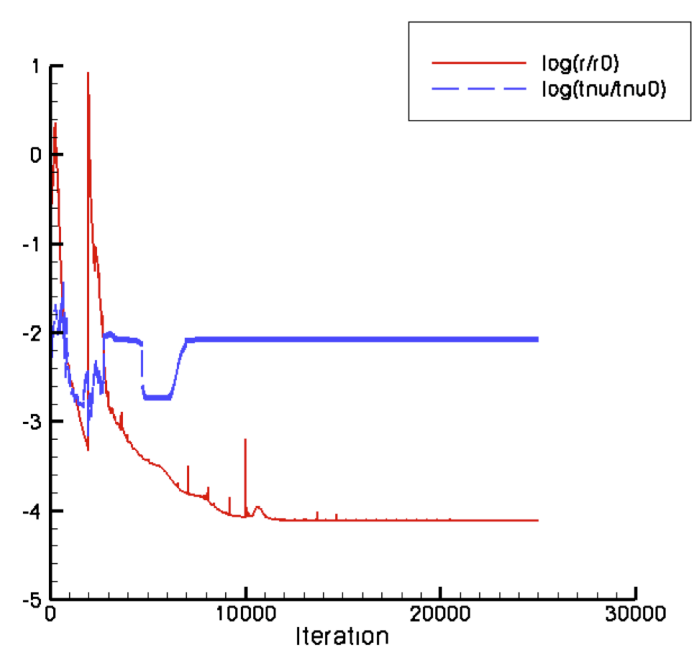

(a) Solution residual histories.

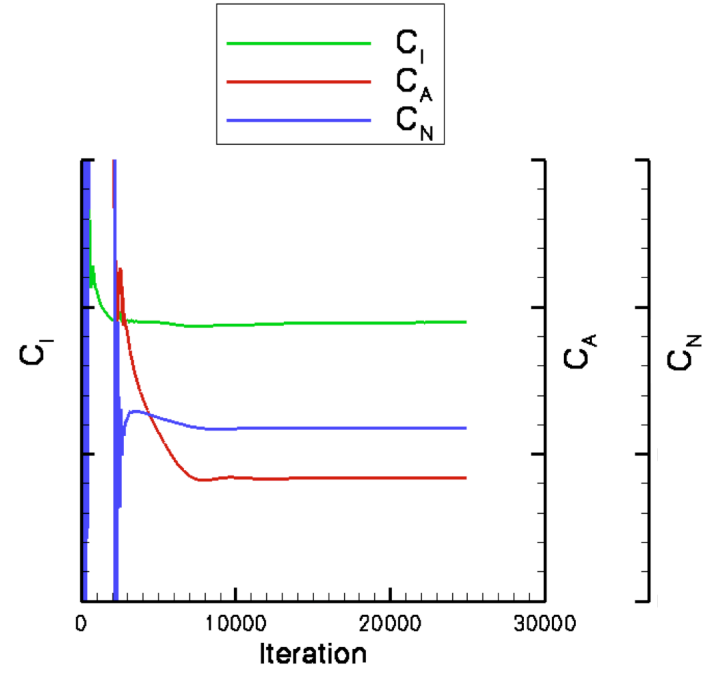

(b) Solution histories of the force and moment coefficients.

Figure 9. Typical convergence plots. $M=1.6, \alpha=7^{\circ}, \phi=0^{\circ}$, clockwise roll action, SST. 
Table 1 shows a typical summary of the force and moment calculations for determining solution convergence. Coefficients shown in Table 1 are not related to any specific flow condition. In reference to these representative coefficient values, the standard deviation and percent over range values for each coefficient demonstrates the degree of convergence attainable in the solution development process. The force and moment coefficients converged well for all 36 solutions listed in Table 2 except two cases: 1) $M=0.9, \alpha=0^{\circ}, \phi=0^{\circ}$, negative rolling moment, SST and 2) $M=0.9, \alpha=7^{\circ}, \phi=0^{\circ}$, negative rolling moment, SST. However, axial force and rolling moment coefficients converged well even for these two cases. The flow condition for the first case was also run with the SA turbulence model and converged well. The fact that the first case $\left(M=0.9, \alpha=0^{\circ}, \phi=0^{\circ}\right.$, negative rolling moment) converged with the SA turbulence model but not with the SST model indicates that there was a numerical instability or unsteady flow present in the solution. A time accurate solution could further determine the source of the oscillations present in the SST case, but the authors made no attempt to run the cases in time accurate mode because of project time and resource constraints for this exploratory study. The coefficients of side force, rolling moment, yawing moment, and pitching moment at $\alpha=0^{\circ}$ could not be measured by the convergence formula to within the conservative 0.5 percent of the mean value because the mean value was practically zero.

Table 1. Typical force and moment coefficient monitoring for convergence.

\begin{tabular}{|c|c|c|c|c|c|c|}
\hline & $\mathbf{C}_{\mathbf{A}}$ & $\mathbf{C}_{\mathbf{Y}}$ & $\mathbf{C}_{\mathbf{N}}$ & $\mathbf{C}_{\mathbf{l}}$ & $\mathbf{C}_{\mathbf{m}}$ & $\mathbf{C}_{\mathbf{n}}$ \\
\hline Average & 2.00000 & 0.005000 & -0.002000 & 0.040000 & 0.050000 & 0.080000 \\
\hline $\begin{array}{c}\text { Standard } \\
\text { Deviation }\end{array}$ & $0.30000 \mathrm{E}-05$ & $0.21000 \mathrm{E}-04$ & $0.62000 \mathrm{E}-05$ & $0.16300 \mathrm{E}-05$ & $0.81000 \mathrm{E}-04$ & $0.18000 \mathrm{E}-03$ \\
\hline $\begin{array}{c}\text { Percent Over } \\
\text { Range }\end{array}$ & 0.0005 & -0.0280 & -0.0010 & 0.0140 & -0.0006 & -0.0270 \\
\hline
\end{tabular}

Table 2. Description of the limited parametric study; 22 flow conditions.

\begin{tabular}{|c|c|}
\hline \multirow{2}{*}{$\begin{array}{c}\text { Wind Tunnel Reynolds Number for } \\
\text { each Mach Number }\end{array}$} & $\mathrm{T}_{\infty}=466.0^{\circ} \mathrm{R} ; \mathrm{Re}=6.9 \mathrm{Million} / \mathrm{ft}$ for $M=0.9$ \\
\cline { 2 - 3 } & $\mathrm{T}_{\infty}=390.0^{\circ} \mathrm{R} ; \mathrm{Re}=6.6 \mathrm{Million} / \mathrm{ft}$ for $M=1.6$ \\
\hline Angle of Attack, $\alpha$ & $0^{\circ}$ and $7^{\circ}$ \\
\hline Vehicle Roll Angle, $\phi$ & $0^{\circ}, 90^{\circ}, 180^{\circ}$ \\
\hline Thruster Pairs & Idle, Firing for Positive and Negative Rolling Moment \\
\hline
\end{tabular}

In the absence of a grid convergence investigation in this study, comparison of the CFD solution to the experimental data could help to quantify the accuracy of CFD solutions from grids constructed in accordance with CLV project best practice. ${ }^{5}$ Figure 10 shows a comparison of CFD solutions for three codes, USM3D, OVERFLOW, and FUN3D, to wind tunnel measured data for the rolling moment coefficient of the ADAC-2A (A101) vehicle one-percent wind tunnel model. This configuration was basically the same as the Ares I-X with some exceptions in the placement of protuberances. Considering that the rolling moment coefficient was two orders of magnitude smaller than the axial force or normal force coefficients, comparisons in terms of point-by-point value or the trend across the vehicle roll angle demonstrated that CFD predictions were capable of producing usable information of vehicle aerodynamic responses along the intended flight trajectory. 


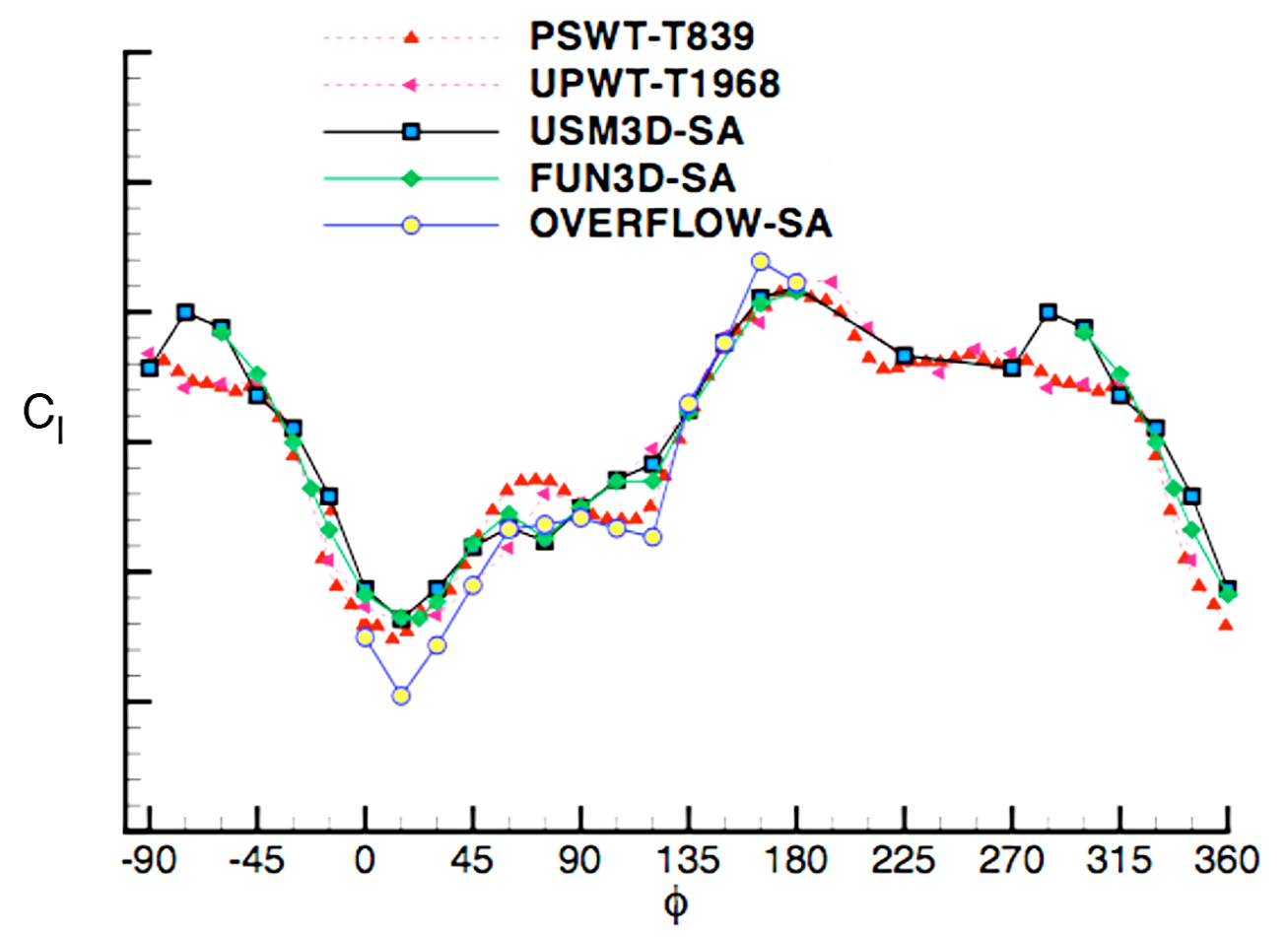

Figure 10. Comparison of rolling moment between CFD and corrected wind tunnel data for the ADAC2A (A101) full protuberance configuration.

\section{Discussion of Results}

\section{A. Flow Conditions for Jet Interaction Assessment}

A limited parametric study was completed at Mach numbers $M=0.9$ and $M=1.6$ for angles of attack $\alpha=0^{\circ}$ and $\alpha=7^{\circ}$ and roll angles of $\phi=0^{\circ}, \phi=90^{\circ}$, and $\phi=180^{\circ}$. The authors computed all cases included in Table 2 using the SST turbulence model. They also computed a few selected flow conditions using the SA turbulence model. The jet interaction effect was determined by the differential between two solutions: a solution with active RoCS and a solution with idle RoCS using an identical grid and free-stream flow condition. This procedure was necessary because the jet interaction effect on rolling moment was a very small number. A bias of the reference value could lead to erroneous conclusions. This procedure was an attempt to exclude most other computational effects not related to thruster firing of the roll control system.

\section{B. Effects of the Turbulence Model}

The effects of the turbulence model on the rolling moment of the simplified Ares I-X configuration were computed with the USM3D flow solver at $M=0.9$ and $M=1.6$ with $\alpha=0^{\circ}, \phi=0^{\circ}$, and with the thrusters fired to generate a negative rolling moment. The SST solution at $\mathrm{M}=0.9$ had converged axial force and rolling moment coefficients. However, other coefficients for that case exhibited signs of unsteadiness. A fully converged solution at $\mathrm{M}=0.9$ was achieved with the SA turbulence model. This could suggest that a certain instability due to flow physics, local grid density, or numerical behavior of the solver was plaguing the $M=0.9 \mathrm{SST}$ solution. At $M=1.6$, both the SA and the SST solutions were very well converged.

Two quantities were compared between the SA and SST solutions at $M=0.9, \alpha=0^{\circ}, \phi=0^{\circ}$, with the thrusters fired for a negative rolling moment. The rolling moment component produced by thrust force measured at the thruster exit faces alone represented the roll control system performance in an ideal situation without jet interaction effects. This component was named "thruster pair" for easy reference in this discussion. There was virtually no difference between the solutions. The second quantity was the total vehicle rolling moment defined as the overall computed rolling moment coefficient minus the direct contributions to $\mathrm{C}_{1}$ by the thruster pair. This component was 
essentially the rolling moment of the entire vehicle configuration geometry including jet interaction effects. The $\mathrm{C}_{1}$ value of this component was 5.3 percent lower for SA versus that of the SST solution.

The comparison of the same two quantities between the SA and the SST solutions at Mach = 1.6 was closer than those at Mach $=0.9$. Again, there was no predicted difference for the thruster pair contribution to $\mathrm{C}_{1}$. The total vehicle geometry component of $\mathrm{C}_{1}$ was 0.5 percent higher for SA than the corresponding SST value.

Figure 11 shows the pressure coefficient flow contours around the RoCS housing for the SA and SST solutions at $M=0.9$. For the SA solution, there was a larger region of low pressure near the incline of the RoCS housing and a smaller region of high pressure along vertical side face, which together caused a larger positive rolling moment than the SST turbulence model solution.

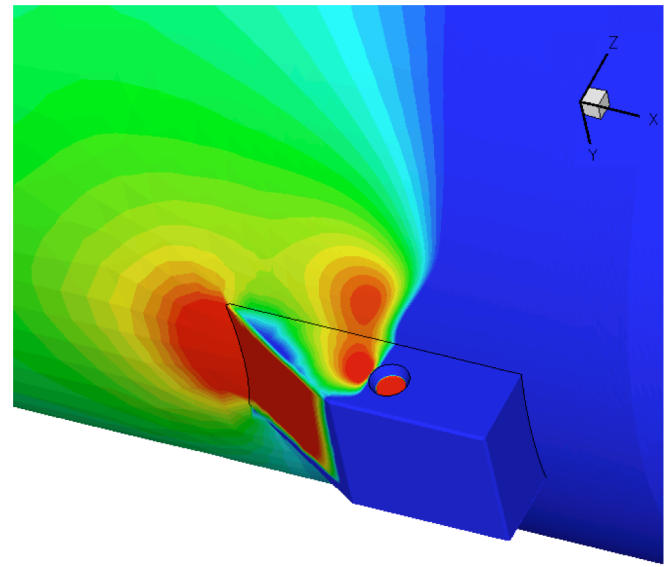

(a) SA turbulence model.

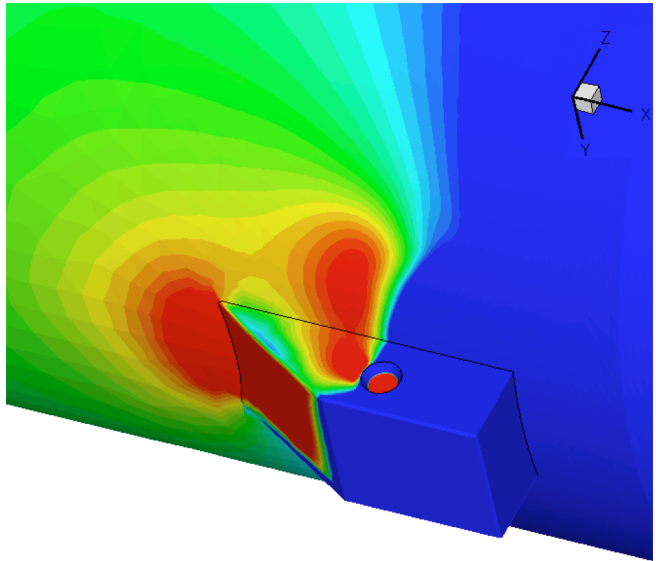

(b) SST turbulence model

Figure 11. Comparison of pressure coefficient contours around RoCS housing at $M=0.9, \alpha=0^{\circ}, \phi=0^{\circ}$, counter-clockwise roll command.

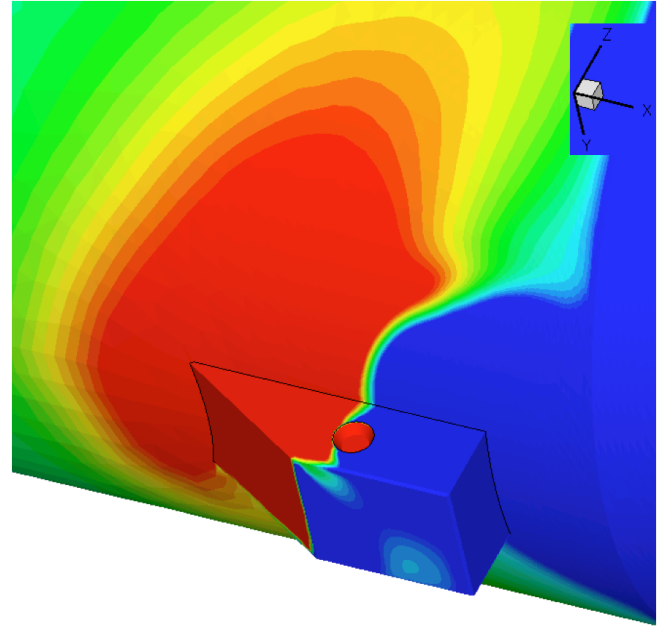

(a) SA turbulence model.

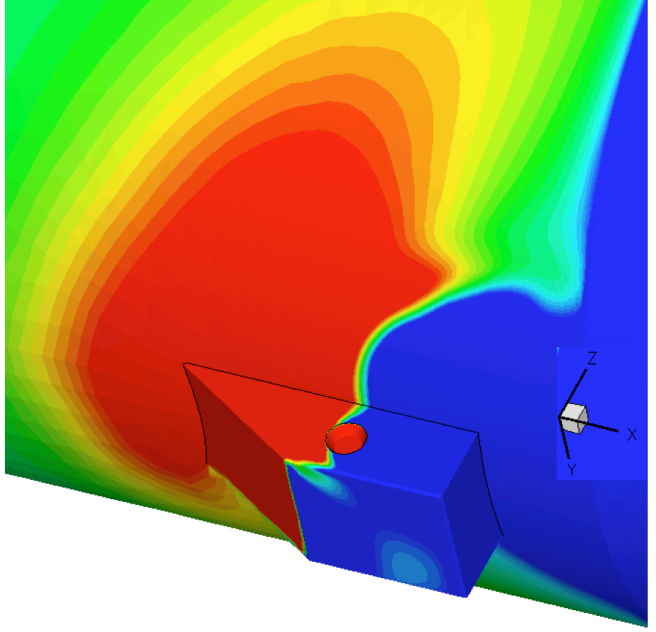

(b) SST turbulence model.

Figure 12. Comparison of pressure coefficient flow contours around RoCS housing at $M=1.6, \alpha=0^{\circ}, \phi=0^{\circ}$, negative roll moment. 
Figure 12 shows the pressure coefficient contours around the RoCS housings for $M=1.6$ using the SA and SST turbulence models. As expected from the closer correlation of the rolling moment contributions between the two turbulence models at $M=1.6$, the pressure coefficient contours were more similar between the two turbulence models than those for $M=0.9$. The comparison between SA and SST of the surface streamlines based on skin friction vector for $M=0.9$ and $M=1.6$ are shown in Fig. 13 and 14, respectively. It is difficult to compare the significance of the streamline pattern differences between these pairs of solutions. However, it is apparent that the helical paths of the streamlines would provide skin friction forces pulling the vehicle in a direction opposite to the commanded rotation for a negative rolling moment.

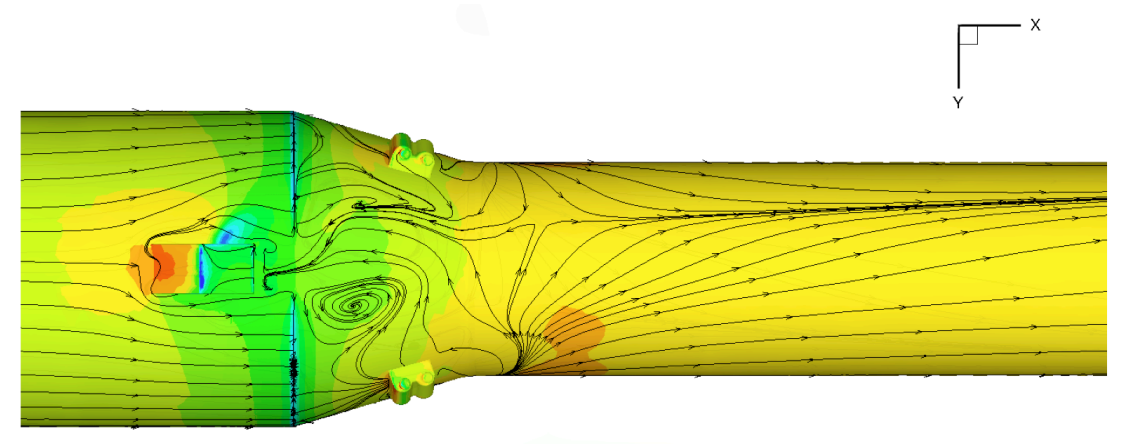

(a) SA turbulence model.

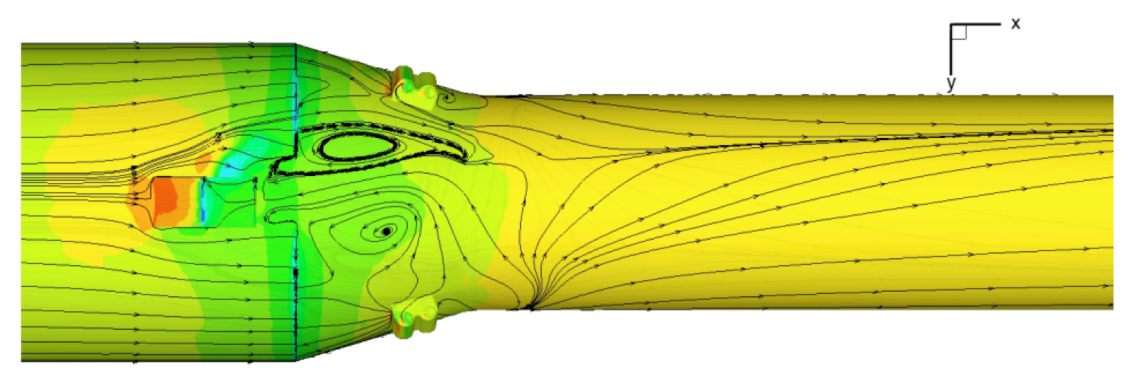

(b) SST turbulence model.

Figure 13. Surface streamlines based on skin friction vector around the interstage, frustum and first stage at $M=0.9, \alpha=0^{\circ}, \phi=0^{\circ}$, with thrusters firing for a negative rolling moment. 


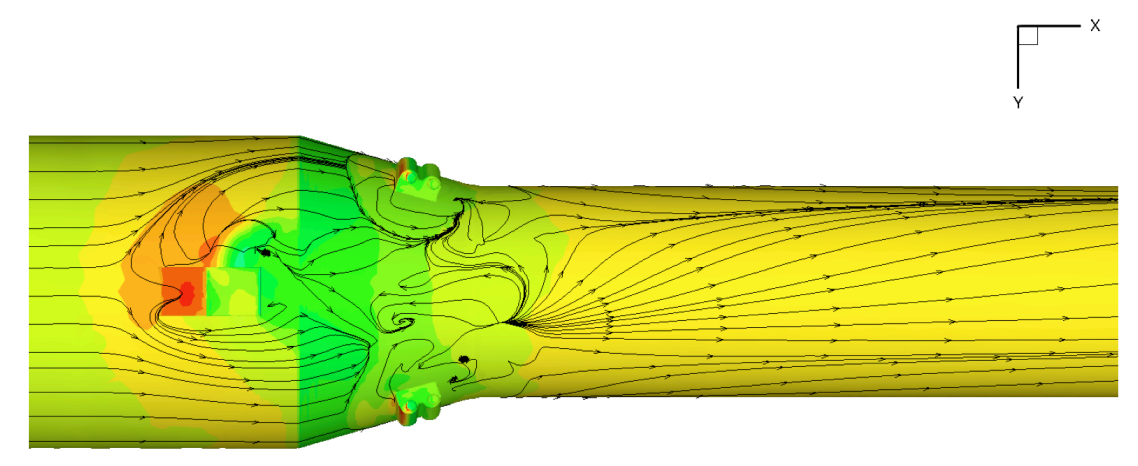

(a) SA turbulence model.

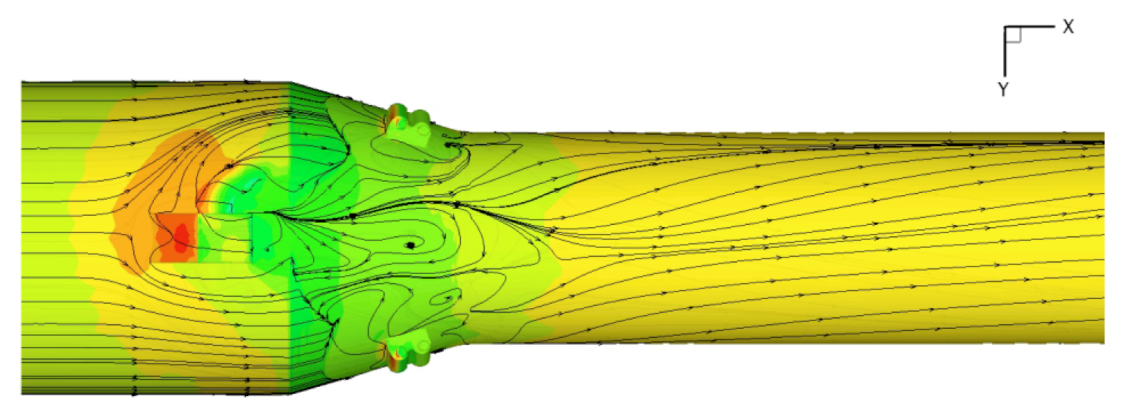

(b) SST turbulence model.

Figure 14. Surface streamlines based on the skin friction vector on the interstage, frustum, and first stage at $M=1.6, \alpha=0^{\circ}, \phi=0^{\circ}$, with thrusters firing for a negative rolling moment.

\section{Comparison to OVERFLOW Solutions}

The best practices established in the Ares project for the CLV work ${ }^{5}$ were used when obtaining the OVERFLOW ${ }^{17-18}$ calculations referred to in this section. Klopfer ${ }^{19}$ at NASA Ames Research Center used the same simplified Ares I-X outer mold line to generate the OVERFLOW grids as was used in generating the USM3D grids. Unlike the unstructured mesh used with the USM3D code, OVERFLOW uses an overset mesh. The overset mesh for this work had approximately 75 million grid points in 47 zones and maintained a $\mathrm{y}^{+}$less than 0.5 on all solid walls. Figure 15 shows a cross section of the overset grid system used with OVERFLOW. The OVERFLOW2.0aa version of the code was used with the 1993 version of the Spalart-Allmaras turbulence model for the current work. Further details of the OVERFLOW code capability, upgrades, and validation may be found in Ref. 16 and 17.

For the current OVERFLOW ideal gas analysis, Klopfer ${ }^{19}$ modeled the RoCS thrusters with a boundary condition at the exit plane of the thrusters but with no internal thruster geometry. The thruster exit plane boundary condition used prescribed flow conditions from Marshall Space Flight Center data interpolated onto the grid system. In contrast, the USM3D thruster boundary condition was inside the divergent section of the thruster with a truncated portion of the divergent section modeled in the computational domain. For both USM3D and OVERFLOW solutions, all solid walls were treated with a no-slip boundary condition and characteristic inflow outflow boundary conditions were used in the far field. In the OVERFLOW mesh, the zonal interface boundaries were interpolated with Pegasus5. The OVERFLOW solutions also followed the best practices for evaluating convergence as established in Ref. 5. Additionally, Klopfer ${ }^{19}$ documented force and moment histories to qualify the degree of convergence of the force and moment coefficients. 


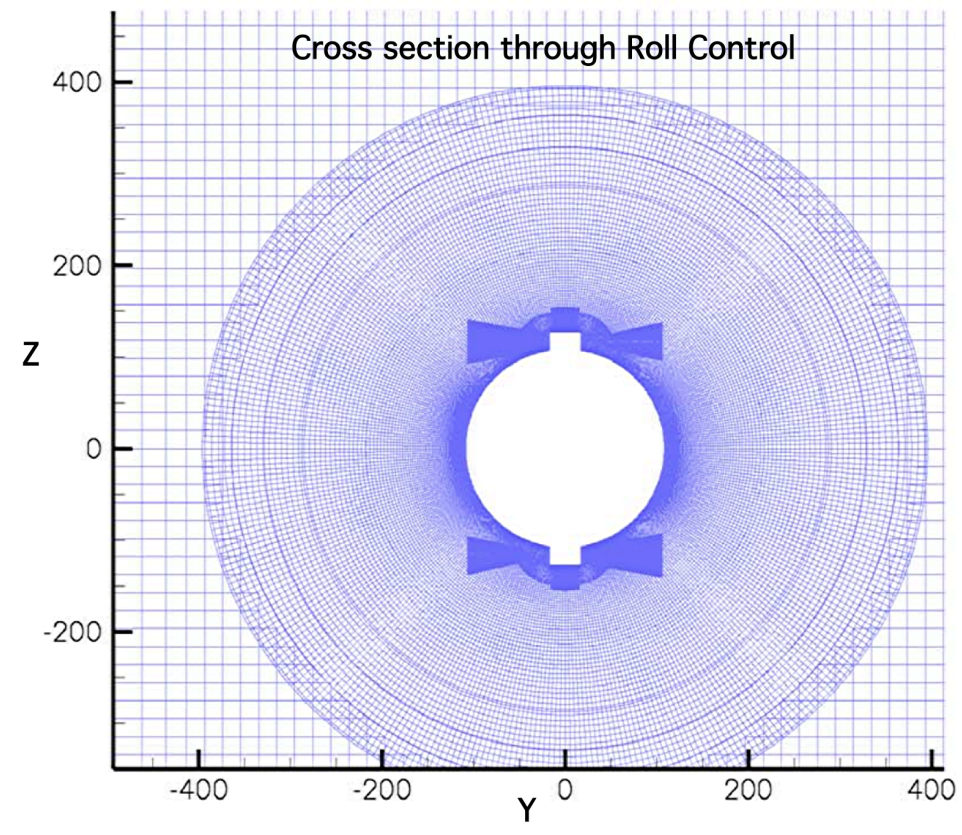

\section{OVERSET GRID SYSTEM}

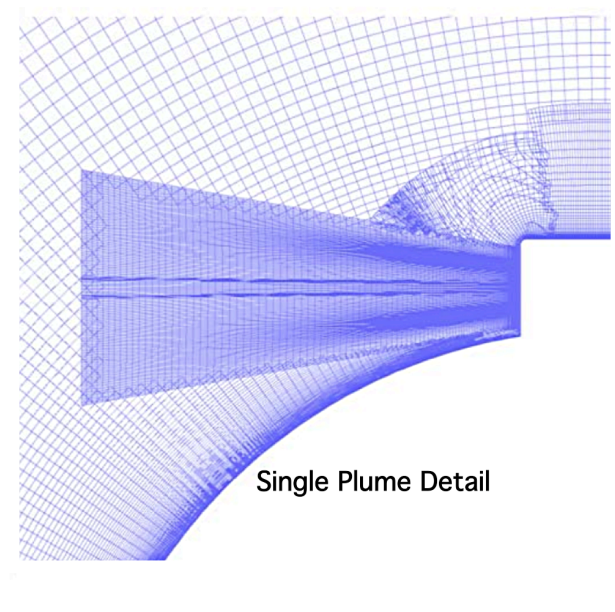

Figure 15. Overset grid for the OVERFLOW solutions.

The OVERFLOW and USM3D data in this comparison were computed with the SA turbulence model and thrusters firing for a positive rolling moment. The authors compared the data at two Mach numbers, $M=0.9$ and $M$ $=1.6$, for $\alpha=7^{\circ}$ and $\phi=0^{\circ}$. The Reynolds number per foot was 6.9 million for both OVERFLOW solutions. For USM3D, the Reynolds number per foot was 6.9 million for $M=0.9$ and 6.6 million for $M=1.6$. The postprocessing tool for USM3D was able to extract the force and moment coefficients contributions of each specific component. However, the OVERFLOW calculations only had force and moment coefficients for the whole vehicle and the rolling moment contribution of the firing thrusters at the exit faces. Therefore, a detailed comparison of components was not available.

Computed force and moment coefficients using OVERFLOW and USM3D are compared at Mach number $M=$ 0.9 and $M=1.6$. The thruster pair contributions to $\mathrm{C}_{1}$ between these two codes differ by less than 0.5 percent at these two Mach numbers. Table 3 shows the comparison of whole vehicle force and moment coefficients for $M=$ 0.9 and $M=1.6$. The axial force and rolling moment coefficients between the two codes differ by as much as 9 percent at $M=0.9$, and less than 1.5 percent at $M=1.6$. Pitching moment differential is about 10 percent. The correlations of side force, normal force, and yawing moment coefficients between the two codes are not good, suggesting that certain flow features are not captured the same way by these two codes.

Table 3. Comparison between OVERFLOW and USM3D of whole vehicle force and moment coefficients, $M$ $=0.9, \alpha=7^{\circ}, \phi=0^{\circ}$.

\begin{tabular}{|c|c|c|c|c|c|c|}
\hline (USM3D - OF) / USM3D & $\mathbf{C}_{\mathbf{A}}$ & $\mathbf{C}_{\mathbf{Y}}$ & $\mathbf{C}_{\mathbf{Z}}$ & $\mathbf{C}_{\mathbf{l}}$ & $\mathbf{C}_{\mathbf{m}}$ & $\mathbf{C}_{\mathbf{n}}$ \\
\hline $\mathbf{M}=0.9, \alpha=7^{\circ}, \phi=0^{\circ}$. & $8.4 \%$ & $-57.6 \%$ & $21.5 \%$ & $-8.7 \%$ & $11.0 \%$ & $51.3 \%$ \\
\hline $\mathbf{M}=1.6, \alpha=7^{\circ}, \phi=0^{\circ}$. & $1.4 \%$ & $-44.5 \%$ & $11.3 \%$ & $-1.0 \%$ & $7.4 \%$ & $-32.7 \%$ \\
\hline
\end{tabular}

\section{Comparison with Loci-CHEM Real Gas Solution}

In an effort to examine how well the ideal gas truncated nozzle approach represented the thrusters in the analysis of the RoCS jet effects on the simplified Ares I-X configuration, Hall ${ }^{20}$ computed a real gas solution with LociCHEM and compared it with the USM3D ideal gas solution. The single comparison of an ideal gas solution to a real gas solution was not expected to validate the use of the ideal gas model but to determine whether the ideal gas model missed any obvious flow phenomenon. 
The Loci-CHEM ${ }^{21-22}$ CFD flow solver developed by Mississippi State can compute chemically reacting mixtures of thermally perfect gases on three-dimensional, mixed element unstructured mesh. Loci-CHEM is a finite volume, Navier-Stokes flow solver with a finite rate and equilibrium chemistry. One and two equation turbulence models are available in the Loci-CHEM code. Veluri, Roy, Hebert, and Luke document in Ref. 21 the validation and accuracy of the Loci-CHEM flow solver on different mesh types using the Method of Manufactured Solutions.

The Loci-CHEM grid had 29.6 million tetrahedral cells. Solutions were computed on the Columbia parallel computing facility at the NASA Advanced Supercomputing (NAS) Division at Ames Research Center. The LociCHEM solution with the real gas approximation converged in approximately 121 hours (wall time) using 128 processors, or approximately 16000 CPU hours. In contrast, the USM3D ideal gas solution converged in 32 hours using 128 processors, or approximately $4100 \mathrm{CPU}$ hours.

A real gas approximation was used because a full chemistry model would have been extremely expensive for modeling the RoCS thrusters on the Ares I-X configuration. The method of approximation simply followed the fundamental principles of thermodynamics for a mixture of thermally perfect gases as shown in many references (Ref. 22, for example). The approximation assumed frozen flow with constant mass fractions and species velocity. The frozen flow replaced a nine-species exhaust model with a single equivalent species model using Eq. 8 and 9. The exhaust gas constant for the real gas approximation was $\mathrm{R}=401.85 \mathrm{~J} /(\mathrm{kg} \cdot \mathrm{K})$, compared with $\mathrm{R}=286.9 \mathrm{~J} /(\mathrm{kg} \cdot \mathrm{K})$ for ideal gas cases. The real gas approximation reduced the governing equations from 15 to 8 equations. As given in reference 20, there was excellent thermodynamic matching between the 9 species mixture and the 1 species approximation.

$$
\begin{gathered}
e=\sum_{i=1}^{N} \frac{\rho_{i}}{\rho} e_{i} \\
\text { MixtureMolecularWeight }=\frac{R_{\text {universal }}}{R_{\text {mixture }}}
\end{gathered}
$$

The USM3D ideal gas analysis was compared with the Loci-CHEM real gas analysis, both using the SST turbulence model at $M=1.6, \alpha=7^{\circ}$, and $\phi=0^{\circ}$, with the thrusters firing for a negative rolling moment. The authors and $\mathrm{Hall}^{20}$ computed both the ideal and the real gas solutions, respectively, on the same simplified Ares I-X configuration. Hall ${ }^{20}$ computed the Loci-CHEM solution on a coarser mesh with a full interior flow path for each of the RoCS thrusters.

Figure 16 shows the comparison of plume development between the solutions with the free-stream flow direction going from right to left. The plume structures are remarkably similar. The plumes exit in a direction normal to the RoCS housings for a short distance but are quickly turned downstream by the supersonic free-stream flow. The plumes flatten out in the low-pressure region over the frustum. The free-stream flow expanding around the corner of the frustum literally sucks the plumes downward toward the vehicle surface. Both the ideal gas and real gas solutions predict a high-pressure region on the front of the RoCS housing, a triangular shaped region of low pressure on the top of the housing, and a low-pressure wake region behind the housing and plume. The major concern for potential differences between real-gas and ideal gas computations is the dynamic behavior of plume development in a cross flow. Figure 16 shows that the plume size, shape, and trajectory for a velocity iso-surface at 3500 fps are similar for the ideal and the real gas solutions. Hence, the cross flow interaction dynamic and plume mixing has been reasonably emulated by the ideal gas model computations using USM3D. As mentioned earlier in Section VII, the ideal gas truncated thruster model matches the average pressure, density, velocity, mass flow rate, and thrust of the real gas motor at the exit plane. Hence, it is expected that global quantities of thruster injected mass and momentum distribution beyond the $3500 \mathrm{fps}$ iso-surface should be similar between real gas and ideal gas CFD simulations. Gas temperature has cooled significantly at this stage, and further flow interaction with the vehicle or free-stream flow can be assumed to follow classical ideal gas Navier-Stokes equations as modeled in either USM3D or Loci-CHEM. 


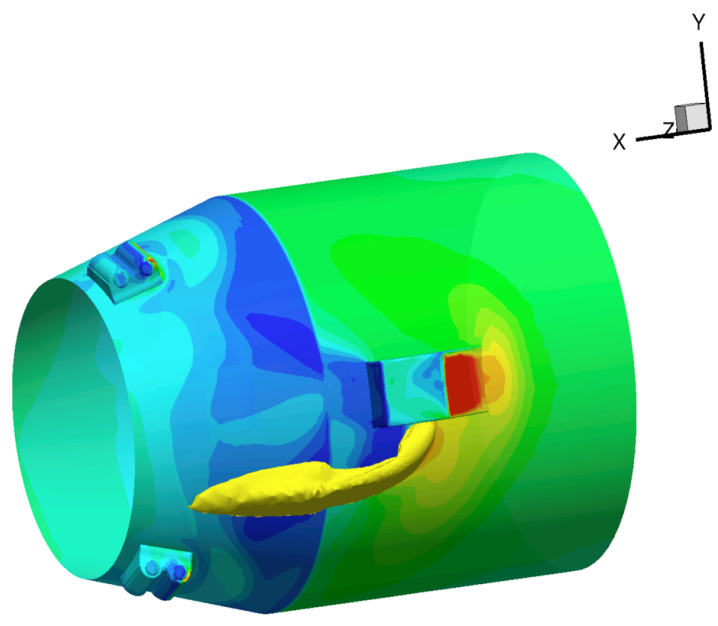

(a) USM3D ideal gas solution.

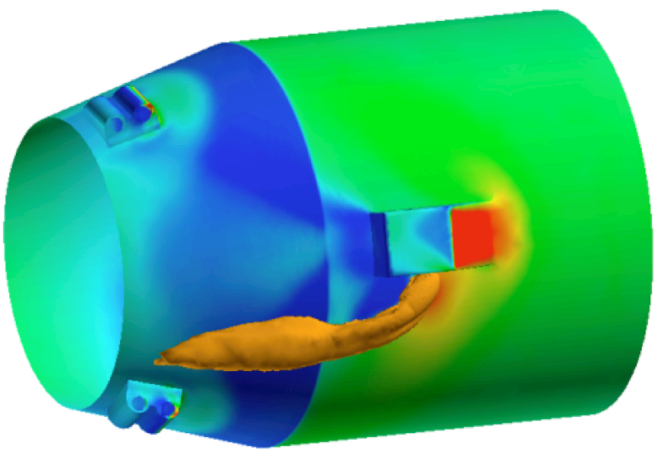

(b) Loci-CHEM real gas solution.

Figure 16. Plume development, $M=1.6, \alpha=7^{\circ}, \phi=0^{\circ}$, counter-clockwise roll; Iso-surface at a constant plume velocity of 3500 fps.

Table 4 shows comparisons of force and moment coefficients between the ideal gas and real gas analyses at $M=$ 1.6, $\alpha=7^{\circ}$, and $\phi=0^{\circ}$, with the thrusters firing for a negative rolling moment. The USM3D firing thrusters (thruster-2 and thruster-4) produced a rolling moment 6.5 percent less than the Loci CHEM real gas thrusters in the designated roll direction. Whole vehicle axial, side, and normal force coefficients for the ideal gas solution are within 5 percent of the real gas solution. However, the whole vehicle rolling moment is 11.6 percent less than the real gas solution. The values of pitching moment and yawing moment are not available for the whole vehicle LociCHEM solutions. It should be noted that the comparison comes from a single solution. Further real gas effect studies are needed for establishing a conclusive understanding of the differences.

Table 4. Percent difference of whole vehicle force and moment coefficients of the ideal gas solution from the real gas solution, $M=1.6, \alpha=7^{\circ}, \phi=0^{\circ}$, negative rolling moment, SST.

\begin{tabular}{|c|c|c|c|c|c|c|}
\hline (USM3D-CHEM) /USM3D & $\mathbf{C}_{\mathbf{A}}$ & $\mathbf{C}_{\mathbf{Y}}$ & $\mathbf{C}_{\mathbf{Z}}$ & $\mathbf{C}_{\mathbf{l}}$ & $\mathbf{C}_{\mathbf{m}}$ & $\mathbf{C}_{\mathbf{n}}$ \\
\hline$M=1.6, \alpha=7^{\circ}, \phi=0^{\circ}$ & $-3.4 \%$ & $-4.8 \%$ & $3.7 \%$ & $-11.6 \%$ & N.A. & N.A. \\
\hline
\end{tabular}

\section{E. Jet Interaction Component Contribution Analysis}

The USM3D solutions using the SST turbulence model were analyzed for the jet interaction effects of the roll control system on a simplified Ares I-X configuration. The post processing software USMC6 extracted the rolling moment of the whole vehicle and of selected components from all the solutions. The important selected components in this simplified configuration for determining RoCS jet effects included the interstage and frustum, the RoCS housing for thrusters 1 and 2 (rocs1), the RoCS housing for thrusters 3 and 4 (rocs2), the dummy booster tumbling motors (dmybtm1 and dmybtm2), the first stage, and the idle or firing thrusters.

The authors computed the jet interaction effects for each component and for the whole vehicle by subtracting the RoCS idle solution from the RoCS firing solution. This was an important step to eliminate any systemic error not related to jet interaction. For example, the vehicle rolling moment at the RoCS idle flow condition was typically small, but not zero. Figure 17 shows the component contributions of the jet interaction effect for the representative flow conditions in the form of color bars. Different colors show individual component in the following order within each flow condition group: first stage, dummy BTM 2 and 1, rocs housing 2 and 1, and interstage plus frustum surfaces. The thruster pair representing the ideal performance of the roll control system has been accounted for separately and is not shown in these figures. 


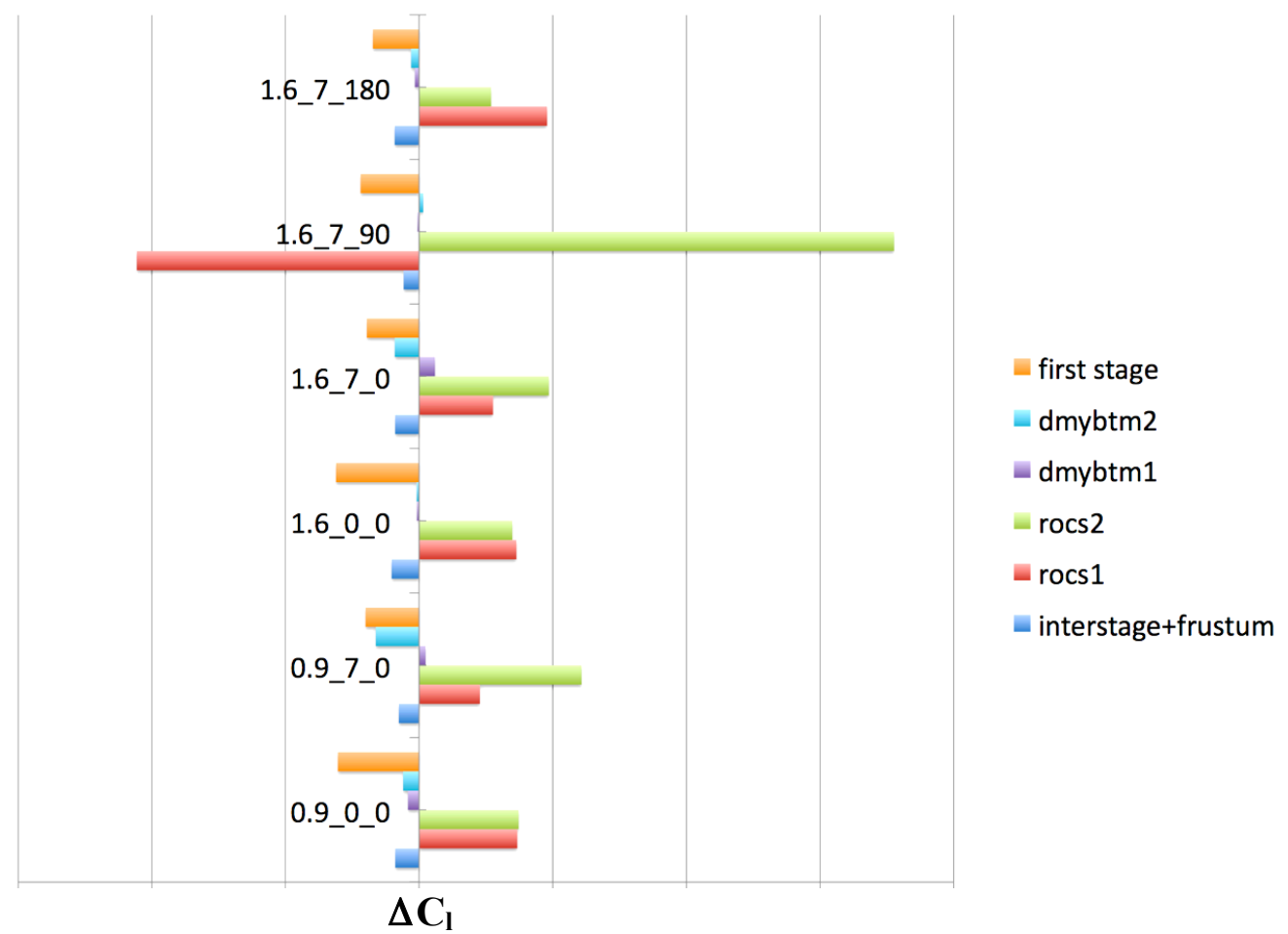

(a) $\Delta \mathbf{C}_{\mathbf{l}}$ for positive rolling moment cases.

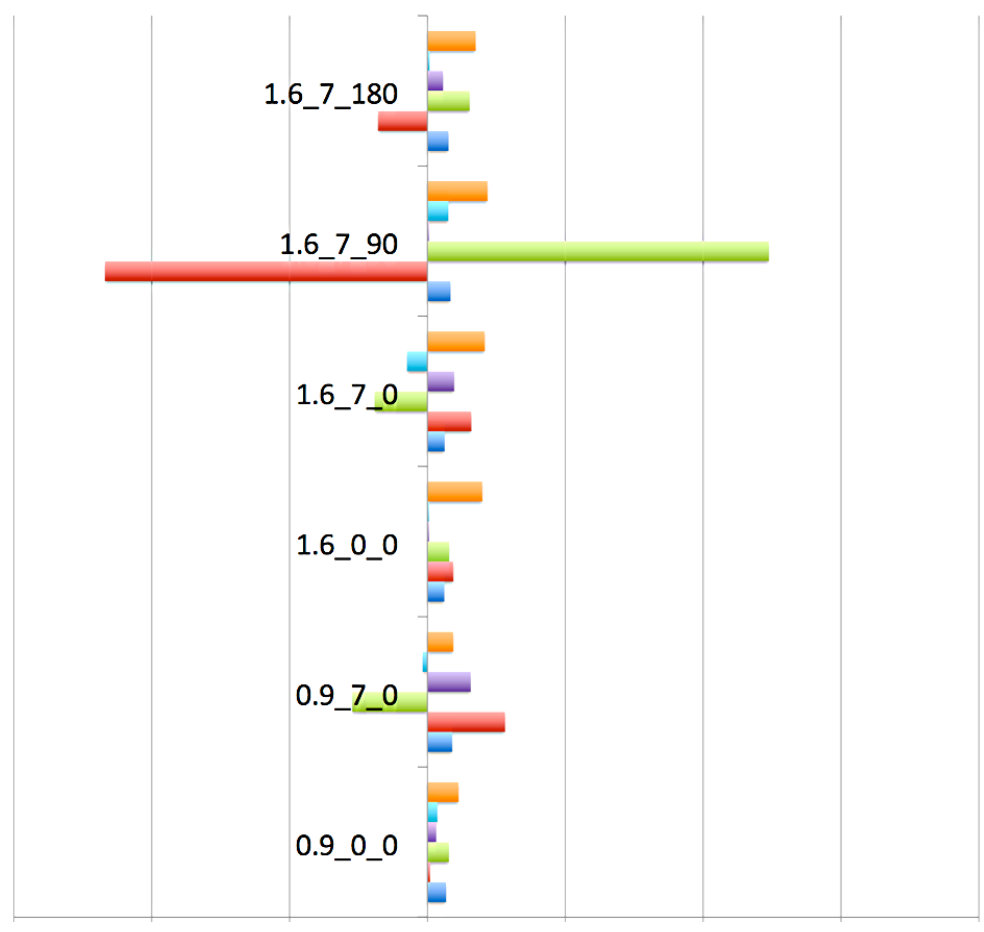

first stage

dmybtm2

dmybtm1

rocs2

rocs1

- interstage+frustum

(b) $\Delta \mathbf{C}_{1}$ for negative rolling moment cases.

Figure 17. Component contributions to $C_{l}$, listed as Mach_ $\alpha \_\phi$.

19

American Institute of Aeronautics and Astronautics 
The dominant contribution to jet interaction was the RoCS housing. When the thrusters were firing, the cross flow interaction between the freestream and the rocket plume created a pressure footprint on the vertical faces of the RoCS housing. In the case of a positive roll command, as shown in Fig. 17a, the jet effect sum totals on the RoCS housings were positive and in the same direction as the commanded moment. Hence, the pressure interaction was beneficial to the positive roll control effort. In the case of a negative roll command, as shown in Fig. 17b, the total jet effects on the housing remained positive and, thus, were in the opposite direction as the commanded negative moment. Hence, the interactions were a penalty to the negative roll control effort.

The contribution of the first stage, interstage, and the frustum was mainly a skin friction differential created by the jet induced flow around the vehicle downstream of the RoCS location because only the skin friction could produce a rolling moment on these cylindrical surfaces concentric with the roll axis. While the jet plume induced flow was in the same direction as the thruster exhaust plume, the incremental rolling moment created by differential skin friction was in a direction opposing the intended roll control moment. Figure 17 indeed shows such a direction for these corresponding component contributions for all flow conditions. The dummy BTM interactions varied with the flow conditions in terms of Mach number, angle of attack, and vehicle roll angle. The dummy BTM interactions contained mostly pressure differentials on the BTM protrusion above the vehicle surface and, perhaps, a tiny fraction of skin friction effect.

The pressure footprint on the RoCS housing vertical side face provides a jet effect benefit for the positive rolling moment cases, but had little impact for the negative rolling moment cases. Shown in figure 18 are the pressure coefficient distributions along the RoCS housing vertical side face for the positive rolling moment, figure 18a, and negative rolling moment, figure $18 \mathrm{~b}$, at $M=1.6, \alpha=7^{\circ}$ and $\phi=0^{\circ}$. There is a jet interaction benefit when firing the RoCS rear thrusters for a positive rolling moment. The force from the large high-pressure region upstream of the RoCS thruster face (white circle) acted in the same direction as the reaction force from the RoCS jet plume. The component $\mathrm{C}_{1}$ contributions of the vertical side faces to rolling moment are both positive for this case, adding to the positive rolling moment generated by the thrusters.

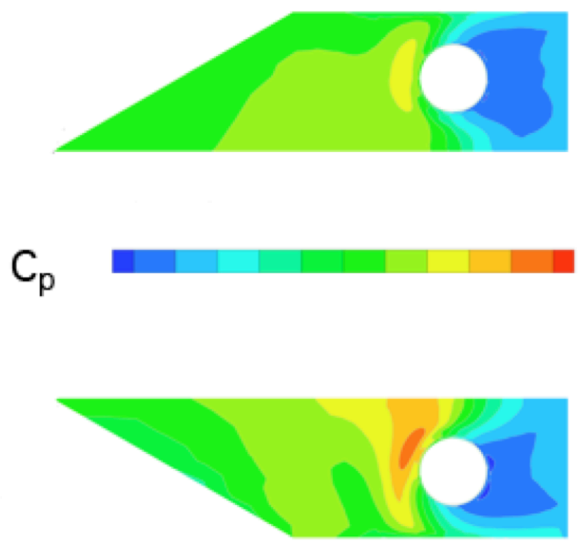

(a) Positive rolling moment.
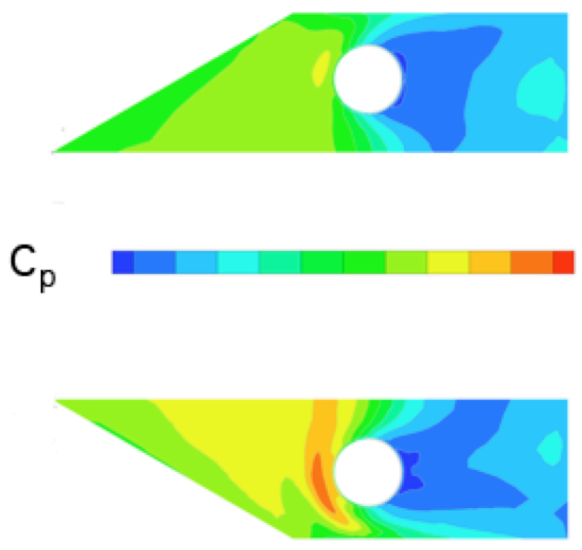

(b) Negative rolling moment.

Figure 18. Pressure coefficient distributions along the RoCS vertical side face for ideal gas analyses, RoCS firing face shown. $M=1.6, \alpha=7^{\circ}, \phi=0^{\circ}$.

As seen in figure 17a, the RoCS housings rocs 1 and rocs 2 have a combined net positive rolling moment contributions, adding to the rolling moment produced by the firing thrusters for all vehicle orientations. In reference to figure 18b, firing the front thrusters for a negative roll causes a large low-pressure region along the vertical side face downstream of the RoCS thruster exit (white circle). Figure 17b shows that the contributions from rocs 1 and rocs2 housings balance against each other. The net contribution to $C_{1}$ is nearly zero. The main message of this flow 
physics analysis shows that pressure distribution on the RoCS housing is an important contributor to jet interaction effect. It should receive careful consideration for vehicle configuration design.

Figure 19 shows the surface streamlines along the frustum and first stage for negative and positive rolling moment cases, $M=1.6, \alpha=7^{\circ}, \phi=0^{\circ}$. The rolling moment contribution of the first stage indicated a jet effects penalty for all of the positive and negative rolling moment cases (Fig. 17). The rocket plume created an induced transverse flow component across the first stage, for which the induced skin friction acted in a direction opposite to the desired roll direction.

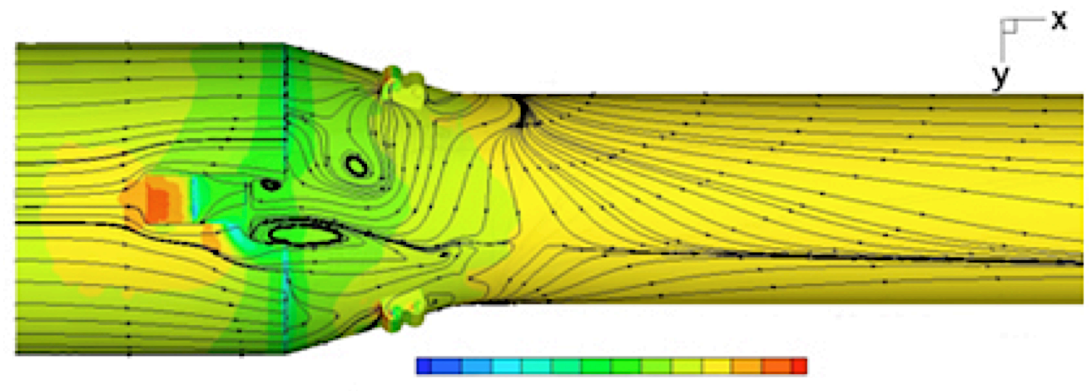

(a) Positive roll.

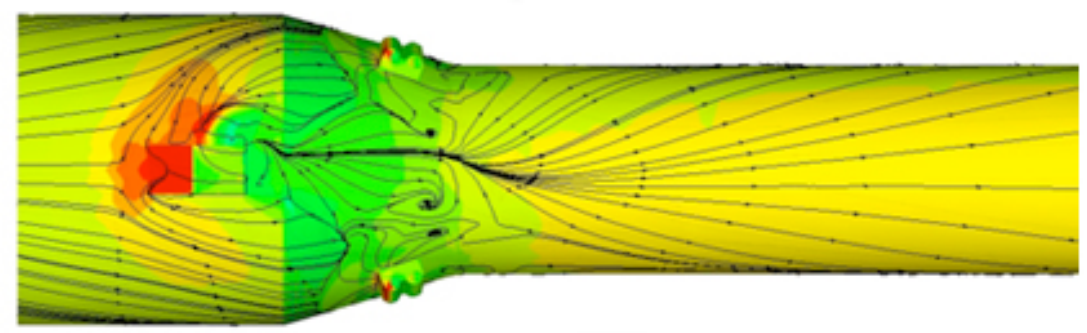

(b) Negative roll.

Figure 19. Surface streamlines based on the skin friction vector on the interstage, frustum, and first stage for negative and positive commanded. $M=1.6, \alpha=7^{\circ}, \phi=0^{\circ}$, ideal gas solutions.

\section{Conclusions}

This study established a methodology for using an ideal gas equivalence to model real gas thruster exhaust plumes of the Ares-type launch vehicle roll control system and the subsequent interaction between the jet plumes, free-stream, and the launch vehicle configuration. The authors conducted a limited parametric analysis of the roll control system jet effects on a simplified Ares I-X configuration using the established methodology as a proof of concept. In this study, the first objective was to select a best practice procedure to simulate the thruster performance by using ideal gas and fixed $\gamma=1.40$ under the code limitations of USM3D at this time. The authors designed the procedure established for this study to match the original rocket thruster performance in terms of average density, pressure, velocity, thrust, and mass flow rate values at the thruster nozzle exit plane. Temperature was not matched because of thermodynamic laws governing gas molecular weight and specific heat ratios. Computational solutions were predicted at two free-stream Mach numbers ( 0.9 and 1.6) with two angles of attack $\left(0^{\circ}\right.$ and $\left.7^{\circ}\right)$ and three roll angles $\left(0^{\circ}, 90^{\circ}\right.$, and $\left.180^{\circ}\right)$. Due to an installation offset in axial locations of the thrusters for clockwise and counterclockwise roll on Ares I-X, the authors performed jet interaction computations for roll thruster firing in both directions at each free-stream flow condition. 
In the initial plan of the solution analysis, the vehicle rolling moment coefficient was assumed to be zero for this simplified vehicle configuration at the thruster idle flow conditions. However, this quantity, though proven small, was not small enough for a clear-cut determination of the sources of the RoCS jet interaction effect. Once the vehicle rolling moment of the idle case was subtracted from the rolling moment of the corresponding thruster firing case, the results were able to identify all the contributing components to the so called jet interation effects. All the contributing components were downstream of the RoCS location for these transonic and supersonic Mach numbers. Interaction from all components upstream of the RoCS location was less than a fraction of one percent of the ideal thruster pair $\mathrm{C}_{1}$ for all case.

The main contributors to the rolling moment jet interaction effects of the roll control system were the vertical side faces of the RoCS housing and the induced flow over the first stage. Whether the contribution on the vertical RoCS housing side faces was a benefit or a penalty depended on the surface pressure distribution. The contribution from the first stage vehicle surface, on account of an increment in skin friction caused by the induced flow of thruster exhaust plume, was always a penalty in all computed cases. This effect was a surprise intuitively, but not a surprise if one considers the aerodynamic scenario where the thruster exhaust plume flow entrainment wraps around the downstream portion of the vehicle in a helical pattern. The rocket plume created an induced transverse flow component across the first stage, for which the induced skin friction acted in a direction opposite to the desired roll direction.

A small number of cases were computed to compare code-to-code variation, turbulence model impacts, ideal versus real gas impacts, and thruster internal geometry modeling impacts. Although the CFD solutions appear accurate and correlate fairly well between the codes, wind tunnel data validation is essential for CFD validation for such complicated flows.

\section{References}

${ }^{1}$ Morris, C. I., “Ares I FS RoCS Installed Roll Performance Analysis.” RCS-RPT-Analysis-098, March 2008.

${ }^{2}$ Ruf, J. H. and Morris, C. I., "Results of ER43 Second Cycle of Analysis on CLV First Stage Roll Control Thruster Effects, Memo number ER43(06-018), October 2006.

${ }^{3}$ Meyer, B., Slaby, M., and Habchi, S., “Ares I-X CFD Roll Analysis” MSFC Contractor's Report, Jacobs Task Order No. 45-010003-CG, CFDRC Project No. 8845, CFD Research Corporation, Huntsville, AL, December 2007.

${ }^{4}$ Daley, P., Meyer, B., Slaby, M., Sheta, E., and Habchi, S., “Ares I-X Roll Control System Plume Effects on Forces and Moments", CFDRC Report Number 8845-01, September 2008.

${ }^{5}$ Pao, S. P., Vatsa, V. N., Abdol-Hamid, K. S., Pirzadeh, S., Samareh, J. A., Klopfer, G. H., Taft, J. R., and Parlette, E. B., "Best Practice for Ascent Aerodynamics Analysis for the Ares I Configurations," Special Session, JANNAF Meeting, Boston, Massachusetts, May 2008.

${ }^{6}$ Gnemmi, P., Schafer, H.-J., "Experimental and Numerical Investigations of a Transverse Jet Interaction on a Missile Body," AIAA Paper 2005-52, January 2005.

${ }^{7}$ Ebrahimi, H. B., "Numerical Investigation of Jet Interaction in a Supersonic Freestream," J. Spacecraft and Rockets, Vol. 45, No.1, February 2008, pp. 95-103.

${ }^{8}$ Graham, M. J., Weinacht, P., Brandeis, J., Angelini, R., “A Numerical Investigation of Supersonic Jet Interaction for Finned Bodies," Army Research Laboratory Report ARL-TR-2312, Aberdeen Proving Ground, MD, December 2000.

${ }^{9}$ Seiler, F., Gnemmi, P., Ende, H., and Schwenzer, M., "Jet Interaction at Supersonic Cross Flow Conditions," Shock Waves, Vol. 12, 2003, pp. 13-23.

10“Ares I-X Flight Test Vehicle Outer Mold Line Definition,” AI1-SYS-OML, November 2007.

${ }^{11}$ Frink, N. T., Pirzadeh, S. Z., Parikh, P. C., Pandya, M. J., and Bhat, M. K., "The NASA Tetrahedral Unstructured Software System," The Aeronautical Journal, Vol. 104, No. 1040, October 2000, pp. $491-499$. (http://tetruss.larc.nasa.gov/docs/CAS0241_OFFICIAL.pdf)

${ }^{12}$ Samareh, J., "GridTool: A Surface Modeling and Grid Generation Tool," Proceedings of the Workshop on Surface Modeling, Grid Generation, and Related Issues in CFD Solutions, CP-3291, NASA, May 1995.

${ }^{13}$ Pirzadeh, S., "Unstructured Viscous Grid Generation By Advancing-Layers Method," AIAA Journal, Vol. 32, No. 8, August 1994, pp. 1735-1737.

${ }^{14}$ Pirzadeh, S., "Structured Background Grids for Generation of Unstructured Grids By Advancing Front Method," AIAA Journal, Vol. 31, No. 2, February 1993, pp. 257-265.

${ }^{15}$ Pao, S. P., A Brief Users' Guide to USMC6-A TetrUSS Grid and Solution Cutter, NASA Langley Research Center, October 2009. 
${ }^{16}$ Pasch, J., "Ares I-X Roll Control System Thrust Prediction Methodology," Contract NNM05AB50C, Task Order 33-020302-CC, January 2008.

${ }^{17}$ Nicols, R. H., Tramel, R. W., and Buning, P. G., "Solver and Turbulence Model Upgrades to OVERFLOW 2 for Unsteady and High-Speed Applications," AIAA Paper 2006-2824, June 2006.

${ }^{18}$ Liou, M.-S., and Buning, P. G., "Contribution of the Recent AUSM Schemes to the OVERFLOW Code: Implementation and Validation," AIAA Paper 2000-4404, Aug. 2000.

${ }^{19}$ Klopfer, G. H.: Ares I-X Roll Control System Jet Interaction Study using OVERFLOW, Informal NASA internal communication, November 2008.

${ }^{20}$ Hall, L.: Ares I-X Roll Control System Jet Interaction Study using Loci-CHEM, Informal communication to NASA Langley Research Center, CRM-Solutions, Inc., Huntsville, Alabama, November 2008.

${ }^{21}$ Veluri, S. P., Roy, C. J., Hebert, S., and Luke, E. A., "Verification of the Loci-CHEM CFD Code Using the Method of Manufactured Solutions," AIAA Paper 2008-661, January 2008.

${ }^{22}$ Walters, R. W., Cinnella, P., Slack, D. C., and Halt, D., "Characteristic-Based Algorithms for Flows in Thermo-Chemical Nonequilibrium," AIAA Paper 90-0393, January 1990. 